OPEN ACCESS

Edited by:

Yohei Okada,

Kio University, Japan

Reviewed by:

Binal Motawar

University of Missouri, United States

Kaviraja Udupa,

National Institute of Mental Health and

Neurosciences, India

${ }^{*}$ Correspondence:

Xia Xu

xuxia@whsu.edu.cn

Specialty section:

This article was submitted to

Motor Neuroscience,

a section of the journal

Frontiers in Human Neuroscience

Received: 12 September 2021 Accepted: 02 November 2021 Published: 30 November 2021

Citation:

Li J, Liu Z, Du Z, Zhu N, Qiu X and $X u X$ (2021) Cortical Activation During Finger Tapping Task Performance in Parkinson's Disease Is Influenced by

Priming Conditions: An ALE Meta-Analysis.

Front. Hum. Neurosci. 15:774656. doi: 10.3389/fnhum.2021.774656

\section{Cortical Activation During Finger Tapping Task Performance in Parkinson's Disease Is Influenced by Priming Conditions: An ALE Meta-Analysis}

\author{
Jingjing $L i^{1}$, Zheng $L i u^{2,3}$, Zhongquan $D u^{1}$, Ningning $Z h u^{1}$, Xueqing Qiu ${ }^{1}$ and $X i a X u^{4,5 *}$ \\ 1 Graduate School, Wuhan Sports University, Wuhan, China, ${ }^{2}$ ANU College of Health and Medicine, Australian National \\ University, Canberra, ACT, Australia, ${ }^{3}$ Sydney School of Education and Social Work, University of Sydney, Sydney, \\ NSW, Australia, ${ }^{4}$ College of Health Science, Wuhan Sports University, Wuhan, China, ${ }^{5}$ Hubei Key Laboratory of Exercise \\ Training and Monitoring, Wuhan Sports University, Wuhan, China
}

The finger tapping task (FIT) is commonly used in the evaluation of dyskinesia among patients with Parkinson's disease (PD). Past research has indicated that cortical activation during FTT is different between self-priming and cue-priming conditions. To evaluate how priming conditions affect the distribution of brain activation and the reorganization of brain function, and to investigate the differences in brain activation areas during FTT between PD patients and healthy control $(\mathrm{HC})$ participants, we conducted an activation likelihood estimation (ALE) meta-analysis on the existing literature. Analyses were based on data from 15 independent samples that included 181 participants with PD and 164 $\mathrm{HC}$ participants. We found that there was significantly more activation in the middle frontal gyrus, precentral gyrus, post-central gyrus, superior parietal lobe, inferior parietal lobule, cerebellum, and basal ganglia during $\mathrm{FTT}$ in PD patients than in HCs. In self-priming conditions, PD patients had less activation in the parietal lobe and insular cortex but more activation in the cerebellum than the HCs. In cue-priming conditions, the PD patients showed less activation in the cerebellum and frontal-parietal areas and more activation in the superior frontal gyrus and superior temporal gyrus than the HCs. Our study illustrates that cue-priming manipulations affect the distribution of activity in brain regions involved in motor control and motor performance in PD patients. In cue-priming conditions, brain activity in regions associated with perceptual processing and inhibitory control was enhanced, while sensory motor areas associated with attention and motor control were impaired.

Keywords: finger tapping task, Parkinson's disease, motor control, self-priming, cue-priming, ALE meta-analysis

\section{INTRODUCTION}

Parkinson's disease (PD) is a common neurodegenerative disease among middle-aged and elderly people. Its clinical features mainly include bradykinesia, rigid muscles, static tremor, postural instability, and gait disorders (Marsden, 1994; Tolosa et al., 2009; for reviews on the history of PD, see Goetz, 2011). These symptoms have significant influences on one's survival, quality of life, and 
nursing home placement demand. The incidence rate of PD in elderly individuals aged over 60-65 years is over $1-2 \%$, and the prevalence increases with age (Hirtz et al., 2007; Elbaz et al., 2016).

Bradykinesia is one of the most common and serious symptoms of PD and is most obviously shown during movement repetition (Bologna et al., 2016). PD patients usually have reduced movement, speed, and amplitude and have difficulties in autonomous movement (Sethi, 2008). The finger tapping task (FTT, also known as a tapping speed assessment) has been one of the most commonly paradigms that used to assess muscle control and motor ability since the nineteenth century (Golden et al., 2002; Picillo et al., 2016). The original FTT paradigm required participants to place their palms flat on a surface and continuously tap with their index finger in blocks of 10-30 s. The number of strokes by a participant was recorded. Over the years, the paradigm has been modified into different forms to suit various conditions (Levit-Binnun et al., 2007; Versaci and Laje, 2021). FTT is affected by many factors including hand dominance, age, gender, and neural control. Neuroimaging studies suggest that the primary motor area of the hand and the cerebellum plays a pivotal role in the control of finger tapping (Jancke et al., 2004). The performance of finger tapping is related to neural mechanisms located in supra-spinal structures (Studenka and Zelaznik, 2011), Normal finger tapping requires the functional integrity of the corticospinal tract, cerebellar motor circuitry, and proprioceptive pathways (Zhang et al., 2018). The usefulness of the finger tapping task for specific PD motor assessment has been proven by evidences showing correlation with the extent of loss of neurons in the substantial nigra, assessed in vivo with [18F]-6-fluoro-L-dopa (6-FD) PET (Pal et al., 2001). The FTT is an effective evaluation index of movement impairments such as bradykinesia in PD patients. When performing the FTT, PD patients tend to show lower tapping speed and a decreased range of motion (Lee et al., 2010; Stegemöller et al., 2015). Owing to their abnormal basal ganglia output, PD patients lack the finer cortical control and greater facilitation that the finger task demands.

For the development of treatment methods, a better understanding of the neurological basis of $\mathrm{PD}$ symptoms is crucial. Previous structural and functional imaging investigations have made preliminary attempts to elucidate the neural basis of bradykinesia in PD patients (Baudrexel et al., 2011; Ziegler et al., 2014; Hirano, 2021). As the FTT has the advantage of being simple and flexible enough to use in the study of both PD patients and healthy controls (HCs), it is often used in functional neuroimaging studies to evaluate the integrity of motor control and neuromuscular system function in PD patients (Witt et al., 2008; Wurster et al., 2015). In recent years, a large number of neuroimaging studies have discovered changes in brain activation during FTT performance in PD patients (Wurster et al., 2015; Bologna et al., 2016). Studies have reported that the structures activated in PD patients during the FTT include the primary motor cortex, supplementary motor area (Jia et al., 2018), parietal lobe (Samuel et al., 1997; Tessa et al., 2013), ventrolateral thalamic nucleus (Mallol et al., 2007), and inferior frontal gyrus (Disbrow et al., 2013). Some studies have refined the activated brain areas to the superior temporal gyrus, inferior frontal gyrus (Cerasa et al., 2006) and middle frontal gyrus (Mak et al., 2016). Areas reported in previous studies to show possible impairments include the sensorimotor cortex (Georgiou et al., 1994; Martin et al., 2019), basal ganglia (Witt et al., 2008; Liberg et al., 2013; Ruppert et al., 2020), thalamus (Samuel et al., 1997; Mak et al., 2016; Jia et al., 2018) and cerebellum (Rowe et al., 2002; Cerasa et al., 2006; del Olmo et al., 2006). Other areas that exhibited insufficient activation are the putamen (Martin et al., 2019), superior parietal lobule, insula cortex (Wu and Hallett, 2005), and striatum (Wu et al., 2011). Some studies have also found insufficient activation in the supplementary motor area (Martin et al., 2019) and primary motor cortex (Hughes et al., 2010). In contrast to impairments, some studies reported greater activation of the primary motor cortex (Yan et al., 2015) and cerebellar regions (Rowe et al., 2002; Yan et al., 2015; Mirdamadi, 2016) during FTT performance in PD patients than in HCs, suggesting possible compensatory connectivity mechanisms in PD.

In summary, the distribution of activated areas and the direction of activation changes in existing studies have been inconsistent (Levit-Binnun et al., 2007; Witt et al., 2008), thus providing an ambiguous picture of the pathophysiological mechanisms of motor control in PD patients. It is difficult to identify clear brain activation patterns of PD patients during FTT performance with these inconsistent and even contradictory neural findings. One reason for the inconsistencies is the use of different priming conditions during the FTT (Georgiou et al., 1994; Lim et al., 2005). Past research has shown that PD patients rely more strongly on external cues in motor control than $\mathrm{HC}$ participants (Georgiou et al., 1994; Mak and Hui-Chan, 2004, 2008). The external cues can be audio cues (e.g., regular rhythms generated by a metronome) (Hackney et al., 2015; Qureshi et al., 2020), visual cues (e.g., flashing lights) (van Eimeren et al., 2006), etc. The FTT condition that is performed in the presence of an external cue is called cue-priming or cue-initiated tapping. The FTT condition that is performed without an external cue is called self-priming or self-initiated tapping. Past studies have indicated that priming manipulations may affect the motor control and motor output of individuals with PD (Morris et al., 1994; Mak et al., 2016), thus impacting the distribution of activity across brain regions.

The small sample sizes and the heterogeneity in sample characteristics in neuroimaging studies also contribute to inconsistencies (Gottlieb and Oudeyer, 2018; Raut et al., 2019). Thus, there is a need for a more systematic approach to integrate the existing results and to accurately describe the brain activation patterns during FTT performance (Poldrack et al., 2011). Although some recent reviews have investigated some of the functional mechanisms underlying motor symptoms in PD (Mirdamadi, 2016; Tahmasian et al., 2017), no quantitative review has focused on the impact of different priming conditions on the distribution of brain region activation in PD. Powerful meta-analysis can be aggregate prior studies together to analyze the characteristics of brain activation in PD patients performing the FTT under different priming conditions, which also makes it possible to compare the brain activation differences between PD and HC participants under 
the same priming conditions. Therefore, the present study used activation likelihood estimation (ALE) meta-analysis, which is a quantitative meta-analytic method that has been widely utilized to determine the stereoscopic brain coordinates that have been consistently active across studies (Turkeltaub et al., 2002; Acar et al., 2018). With an ALE analysis, we aimed to study the influence of priming conditions on brain activation during FTT performance in PD patients and to analyze the influence of cue priming on brain activity and functional reorganization ofPD patients. In this way, we hope to contribute to the current understanding of the functional differentiation of brain areas involved during FTT performance in PD patients, which has practical implications for designing future interventions for their treatment.

\section{MATERIALS AND METHODS}

\section{Literature Search and Inclusion Criteria}

The current meta-analysis utilized anonymity data so that it was exempt from approval by the ethics committee of the authors' institution.

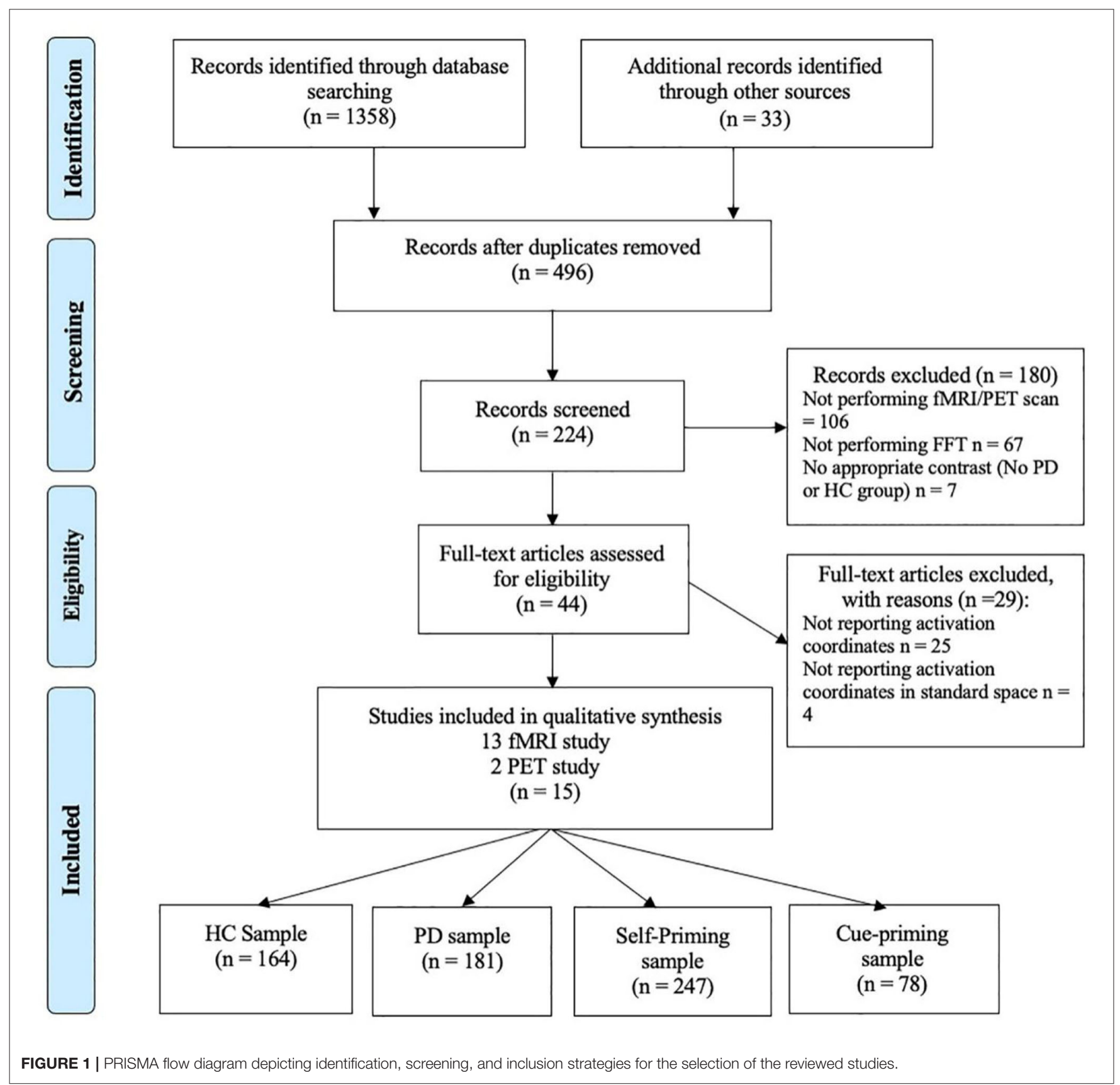


TABLE 1 | Characteristics of the studies included in the meta-analysis.

\begin{tabular}{|c|c|c|c|c|c|c|c|c|c|}
\hline No. & Experiment & Pacing type & $\begin{array}{l}\text { Imaging } \\
\text { method }\end{array}$ & $\begin{array}{c}\text { Number of PD } \\
\text { participants }\end{array}$ & $\begin{array}{c}\text { Number of } \mathrm{HC} \\
\text { participants }\end{array}$ & $\begin{array}{l}\text { UPDRS off } \\
\text { score }\end{array}$ & $\begin{array}{l}\text { UPDRS on } \\
\text { score }\end{array}$ & $\begin{array}{c}\text { Mean age } \\
\text { PD }\end{array}$ & Mean age $\mathrm{HC}$ \\
\hline \multirow[t]{2}{*}{1} & Samuel et al., 1997 & Self-priming ${ }^{1}$ & PET & 6 & 6 & 17.7 & & 70.2 & 64.3 \\
\hline & Samuel et al., 1997 & Self-priming ${ }^{2}$ & PET & 6 & 6 & 17.7 & & 70.2 & 64.3 \\
\hline 2 & Sabatini et al., 2000 & Self-priming & fMRI & 6 & 6 & 16 & & 61 & 59 \\
\hline 3 & Rowe et al., 2002 & Cue-priming & $\mathrm{fMRI}$ & 12 & 12 & 33.7 & & 62 & 62 \\
\hline 4 & Wu and Hallett, 2005 & Self-priming & fMRI & 12 & 12 & 25.5 & & 61.2 & 61.8 \\
\hline \multirow[t]{2}{*}{5} & Cerasa et al., 2006 & Cue-priming & fMRI & 10 & 11 & 27.5 & & 62.4 & 63.4 \\
\hline & Cerasa et al., 2006 & Self-priming & $\mathrm{fMRl}$ & 10 & 11 & 27.5 & & 64.2 & 63.4 \\
\hline 6 & Mallol et al., 2007 & Self-priming & $\mathrm{fMRI}$ & 13 & 11 & 22.6 & & 64.9 & 61.9 \\
\hline 7 & Hughes et al., 2010 & Self-priming & $\mathrm{fMRI}$ & 16 & 15 & 31.3 & 18.9 & 63.9 & 66.5 \\
\hline \multirow[t]{2}{*}{8} & Wu et al., 2011 & Self-priming ${ }^{1}$ & $\mathrm{fMRI}$ & 15 & 15 & 20.7 & & 59.7 & 60.3 \\
\hline & Wu et al., 2011 & Self-priming ${ }^{2}$ & $\mathrm{fMRl}$ & 15 & 15 & 20.7 & & 59.7 & 60.3 \\
\hline \multirow[t]{2}{*}{9} & $\begin{array}{l}\text { González-García et al., } \\
2011\end{array}$ & Cue-priming & fMRI & 17 & 10 & & 41 & 64.4 & \\
\hline & $\begin{array}{l}\text { González-García et al., } \\
2011\end{array}$ & Self-priming & $\mathrm{fMRI}$ & 17 & 10 & & 41 & 64.4 & \\
\hline 10 & Disbrow et al., 2013 & Cue-priming & $\mathrm{fMRI}$ & 13 & 13 & & & 57.5 & 63.9 \\
\hline 11 & Tessa et al., 2013 & Self-priming & $\mathrm{fMRI}$ & 11 & 10 & 13.5 & & 67.7 & 64.0 \\
\hline 12 & Yan et al., 2015 & Cue-priming & fMRI & 11 & 12 & 20.1 & & 61.5 & 65.5 \\
\hline \multirow[t]{2}{*}{13} & Mak et al., 2016 & Self-priming & $\mathrm{fMRI}$ & 27 & 28 & 29.0 & & 61.4 & 60.9 \\
\hline & Mak et al., 2016 & Cue-priming & $\mathrm{fMRI}$ & 27 & 28 & 29.0 & & 61.4 & 60.9 \\
\hline 14 & Jia et al., 2018 & Self-priming & fMRI & 22 & 22 & 16.5 & & 61.0 & 60.6 \\
\hline 15 & Martin et al., 2019 & Self-priming & $\mathrm{fMRI}$ & 22 & 22 & 19.6 & & 53.0 & 48.5 \\
\hline
\end{tabular}

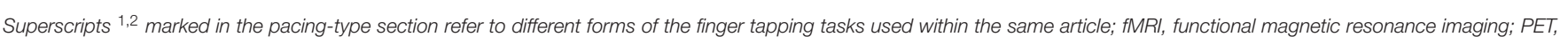

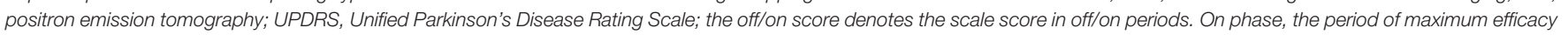
of dopaminergic drugs; OFF phase, the period when PD symptoms appear again.

After determining the research topic, a systematic search was conducted following the Preferred Reporting Items for Systematic Reviews and Meta-Analyses (PRISMA) guidelines (Moher et al., 2009). The targeted online databases were PubMed, ISI Web of Science, and EBSCO Academic Resource Retrieval Center (ASP and BSP). The search terms were ("Parkinson's disease" OR "Parkinson's disease" OR "Parkinson's disease") AND ("functional magnetic resonance" OR "fMRI" OR "positron emission tomography" OR "PET") AND ("tap" OR "tapping" OR "finger" OR "finger tap" OR "finger tapping" OR "Motor control"). To identify papers that might have been missed, several other sources were screened, including the citation index of the BrainMap database (http://BrainMap.org), pre-print articles (https://psyarxiv.com/) and their reference lists. The first search was carried out on July 1st, 2020. The broad search yields 1,358 articles.

After deleting duplicate studies, 496 articles remained. All articles were assessed by two independent raters to decide on the eligibility of studies. Weekly consensus meetings were held, and only articles that both raters agreed on were included in the meta-analysis. A total of 224 articles were determined to be relevant to the topic of this study. By examining the abstracts of the articles, 44 articles were able to proceed to full-text review according to the inclusion criteria and exclusion criteria. The inclusion criteria were as follows: (1) the original research paper was published in a peer-reviewed journal; (2) participants included at least one PD group and one HD group contrast; (3) descriptive statistics of the FTT were reported; and (4) fMRI or PET scans were performed. The exclusion criteria were as follows: (1) severity of the disease (UPDRS score ${ }^{1}$ or H\&Y score ${ }^{2}$ ) was not reported; (2) no specific activation coordinates were reported; and (3) activation coordinates were not in standard space (MNI or Talairach). After applying the exclusion and inclusion criteria, a final set of 15 papers (13 fMRI studies, 2 PET studies), including a total of $181 \mathrm{PD}$ patients and $164 \mathrm{HC}$ participants, were included in the final analysis. The detailed retrieval process is shown in Figure 1.

\section{Coding of Studies}

Two independent coders extracted the basic information (authors, year of publication) for all included studies and compiled a table of study characteristics based on FTT pacing conditions (self-priming or cue-priming), imaging methods, sample size, mean age, and UPDRS scores. A third coder was responsible for the verification. Inconsistencies were rereviewed by the three coders together until consensus was reached. After coding all the targeted elements, a full listing of the

\footnotetext{
${ }^{1}$ The Unified Parkinson's Disease Rating Scale (UPDRS) was introduced in 1987, which is used to monitor the course of Parkinson's disease and the degree of disability (Helme, 1987).

${ }^{2}$ The Hoehn and Yahr scale (H\&Y scale) was originally developed in 1967 and is used to measure the level of disability in PD (Hoehn and Yahr, 1967).
} 

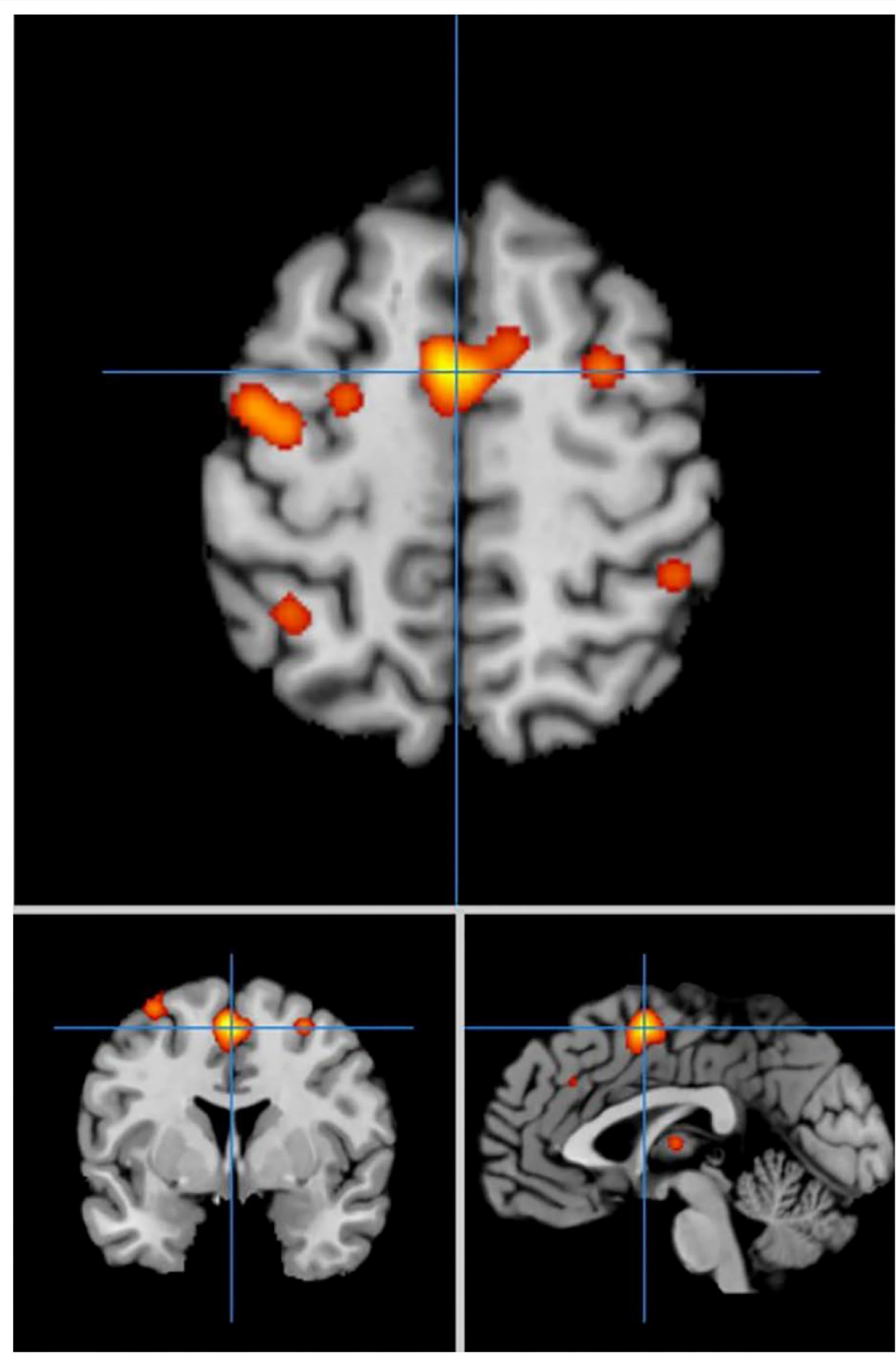

FIGURE 2 | Significant clusters in the ALE meta-analysis in self-priming conditions in the PD patients. 
studies included in the meta-analyses and their corresponding demographic information was compiled and is shown in Table $\mathbf{1 .}$

\section{Meta-Analytic Procedure}

For the analysis, the ALE method is used. It is one of the most commonly used methods for meta-analysis across different brain imaging studies (Turkeltaub et al., 2002). The ALE analysis assumes that for every study of interest, there must be a given spatial distribution of activity and a set of associated maximum coordinates (Laird et al., 2009). In this study, we followed the algorithm proposed by Turkeltaub et al. (2012). It provides a means of evaluating this hypothesis within the framework of a permutation test and is thus able to pinpoint areas of the brain that are more reliably activated across studies. All ALE analyses were run using GingerALE 3.0.2 (http:// www.brainmap.org/ale/). The coordinates of brain activation regions were extracted from the original papers. To allow for direct comparisons of spatial brain coordinates across studies, relevant foci were converted from the Talairach coordinates into MNI coordinates using the Lancaster transform (Lancaster et al., 2007). These foci are modeled as the center of a threedimensional Gaussian probability distribution. With a cluster threshold of $k=120 \mathrm{~mm}^{3}$, all individual analyses were adjusted for multiple comparisons using the false discovery rate (FDR) $p<0.01$ with 5,000 permutations (Turkeltaub et al., 2002, 2012; Laird et al., 2010). The resulting ALE maps were overlaid on the Colin brain template in MNI space and visualized by Mango 4.1 (rii.uthscsa.edu/mango) (Eickhoff et al., 2012). The coordinate points beyond the template boundary were uniformly deleted.

\section{RESULTS}

\section{Description of the Demographic Information}

Fifteen studies (13 fMRI, 2 PET) were included in the ALE meta-analysis. Twenty experiments were reported, with a total sample size of 345 people (181 PD patients). The experiments were divided into four subgroups: the PD selfpriming group, $\mathrm{PD}$ cue-priming group, HC self-priming group, and HC cue-priming group. Study characteristics and participant demographics are summarized in Table 1. The UPDRS (ON) score of the PD participants included in the study was $22.86 \pm 5.97$, which was equivalent to stages III of the Hoehn-Yahr scale, indicating mild to moderate disease severity of the participants. There was no significant age difference between the $\mathrm{PD}$ group $\left(M_{\text {age }}=62.29, S D_{\text {age }}=\right.$ $4.00)$ and HC group $\left(M_{\text {age }}=61.75, S D_{\text {age }}=3.88\right)(t=0.83$, $p=0.42)$.

\section{ALE Meta-Analysis Results}

An ALE analysis was used to determine the cluster of the most significant activation points in the brain activation map and activation regions during finger tapping. The anatomical location and Brodmann area (BA) of each cluster was defined. In the 20 experiments included in the analysis, a total of 160 activation points were identified during performance of the FTT. The largest clusters of activation were located in the middle frontal gyrus, precentral rgyrus, post-central gyrus, superior parietal lobe, inferior parietal lobule, cerebellum, and basal ganglia. These regions are considered the core regions involved in FTT performance in the PD patients.

TABLE 2 | Clusters of activation in self-priming conditions in the PD patients.

\begin{tabular}{|c|c|c|c|c|c|c|c|}
\hline \multirow{2}{*}{$\begin{array}{l}\text { Activation cluster } \\
\# 1\end{array}$} & \multicolumn{2}{|c|}{ Anatomical region } & \multirow{2}{*}{$\begin{array}{l}\text { BA Area } \\
\text { BA } 8\end{array}$} & \multirow{2}{*}{$\begin{array}{c}\mathbf{x} \\
38\end{array}$} & \multirow{2}{*}{$\begin{array}{c}\mathbf{y} \\
32\end{array}$} & \multirow{2}{*}{$\begin{array}{l}\mathbf{z} \\
50\end{array}$} & \multirow{2}{*}{$\begin{array}{c}\text { ALE } \\
0.005\end{array}$} \\
\hline & $\mathrm{R}$ & Superior frontal gyrus & & & & & \\
\hline \#2 & $\mathrm{R}$ & Middle frontal gyrus & BA 6 & 38 & -6 & 46 & 0.005 \\
\hline \#3 & $\mathrm{L}$ & Middle frontal gyrus & BA 6 & -24 & -4 & 56 & 0.0072 \\
\hline$\# 4$ & $\mathrm{R}$ & Transverse temporal gyrus & BA 41 & 58 & -22 & 10 & 0.0065 \\
\hline$\# 5$ & $\mathrm{R}$ & Cingulate gyrus & BA 32 & 10 & 30 & 42 & 0.005 \\
\hline$\# 8$ & $L$ & Medial frontal gyrus & BA 6 & -2 & 0 & 56 & 0.0109 \\
\hline$\# 9$ & $\mathrm{~L}$ & Superior temporal gyrus & BA 41 & -60 & -24 & 14 & 0.0068 \\
\hline$\# 10$ & $\mathrm{R}$ & Middle temporal gyrus & BA 21 & 66 & -46 & -2 & 0.0079 \\
\hline$\# 11$ & $L$ & Thalamus & & -4 & -12 & 6 & 0.0069 \\
\hline$\# 12$ & $L$ & Superior parietal lobule & BA 40 & -36 & -50 & 56 & 0.0069 \\
\hline$\# 16$ & $\mathrm{R}$ & Post-central gyrus & BA 2 & 54 & -28 & 40 & 0.0074 \\
\hline \#17 & L & Post-central gyrus & BA 2 & -42 & -20 & 48 & 0.0071 \\
\hline
\end{tabular}

$R$, right hemisphere; $L$, left hemisphere; $B A$, Brodmann Area. 

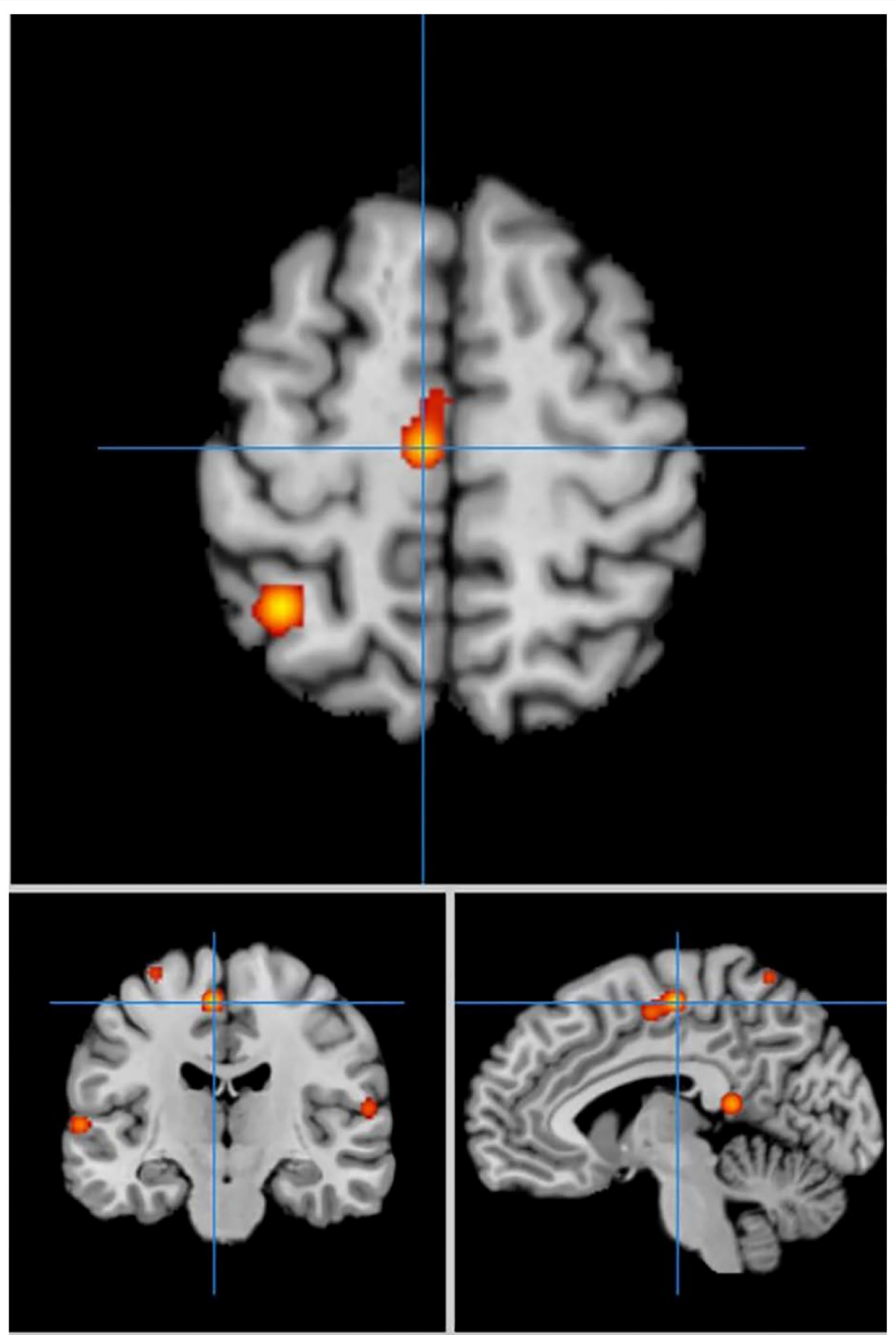

FIGURE 3 | Significant clusters in the ALE meta-analysis in cue-priming conditions in the PD patients. 
TABLE 3 | Clusters of activation in cue-priming conditions in the PD patients.

\begin{tabular}{|c|c|c|c|c|c|c|c|}
\hline Activation cluster & & Anatomical region & BA area & $\mathbf{x}$ & $\mathbf{y}$ & $\mathbf{z}$ & ALE \\
\hline$\# 1$ & $\mathrm{~L}$ & Precuneus & BA 7 & -10 & -58 & 66 & 0.0069014 \\
\hline \#2 & $\mathrm{R}$ & Inferior frontal gyrus & BA 47 & 52 & 32 & -12 & 0.0065224 \\
\hline \#3 & $L$ & Inferior frontal gyrus & BA 45 & -54 & 26 & 0 & 0.0065673 \\
\hline \#4 & $\mathrm{R}$ & Middle frontal gyrus & BA 6 & 46 & 6 & 38 & 0.0069025 \\
\hline \#5 & $\mathrm{L}$ & Middle frontal gyrus & BA 9 & -30 & 38 & 18 & 0.0069257 \\
\hline \#6 & $\mathrm{R}$ & Transverse temporal gyrus & BA 41 & 60 & -22 & 10 & 0.0064963 \\
\hline \#7 & $\mathrm{L}$ & Medial frontal gyrus & BA 6 & -6 & -18 & 56 & 0.0070025 \\
\hline \#8 & $\mathrm{L}$ & Superior temporal gyrus & BA 41 & -62 & -20 & 4 & 0.0063104 \\
\hline \#9 & $\mathrm{R}$ & Middle temporal gyrus & BA 37 & 60 & -60 & 4 & 0.0069014 \\
\hline \#10 & $\mathrm{L}$ & Middle temporal gyrus & BA 37 & -52 & -58 & 8 & 0.0069014 \\
\hline \#11 & $\mathrm{L}$ & Ventrolateral thalamic nucleus & & -12 & -12 & 4 & 0.0065658 \\
\hline \#12 & $\mathrm{R}$ & Superior parietal lobule & BA 7 & 44 & -52 & 62 & 0.0069033 \\
\hline \#13 & $L$ & Superior parietal lobule & BA 7 & -38 & -54 & 62 & 0.0079067 \\
\hline$\# 14$ & $L$ & Posterior cingulate cortex & BA 29 & -4 & -42 & 12 & 0.0069014 \\
\hline \#15 & $\mathrm{R}$ & Posterior lobe of cerebellum VI & & 48 & -62 & -22 & 0.0070793 \\
\hline \#16 & $L$ & Posterior lobe of cerebellum VI & & -50 & -68 & -18 & 0.0067592 \\
\hline$\# 17$ & $\mathrm{~L}$ & Anterior lobe & & -18 & -52 & -30 & 0.0069014 \\
\hline \#18 & $\mathrm{R}$ & Anterior lobe & & 22 & -54 & -28 & 0.0069014 \\
\hline \#19 & $\mathrm{R}$ & Lingual gyrus & BA 18 & 14 & -92 & -8 & 0.0069014 \\
\hline \#20 & $\mathrm{R}$ & Pre-central gyrus & BA 4 & 60 & -2 & 44 & 0.0064317 \\
\hline \#21 & $\mathrm{L}$ & Pre-central gyrus & BA 4 & -30 & -22 & 68 & 0.0065661 \\
\hline
\end{tabular}

\section{ALE Meta-Analysis Results With the PD Group in Different Priming Conditions}

In self-priming conditions, a total of $74 \mathrm{PD}$ patients in 7 experiments were included in the meta-analysis, obtaining 61 activation points (Figure 2). There were 17 clusters of activation, which were located in the cerebellum; both sides of the middle frontal gyrus, cingulate gyrus, medial frontal gyrus, and post-central gyrus; the right side of the superior frontal gyrus, transverse temporal gyrus, inferior parietal lobule, and precuneus; and the left side of the superior temporal gyrus, thalamus, and superior parietal lobule (Table 2).

In cue-priming conditions, a total of $33 \mathrm{PD}$ participants in 3 experiments were included in the meta-analysis, obtaining 28 activation points (Figure 3). There were 21 clusters of activation, which were located on both sides of the inferior frontal gyrus, middle frontal gyrus, middle temporal gyrus, superior parietal lobe, posterior lobe of cerebellum VI, cerebellum, and precentral gyrus; the left side of the precuneus, medial frontal gyrus, superior temporal gyrus, posterior cingulate cortex, and ventrolateral thalamic nucleus; and the right side of the transverse temporal gyrus and lingual gyrus (Table 3 ).

Comparing the activated regions between the self-priming and cue-priming conditions, the middle frontal gyrus, pre-central gyrus, superior parietal lobule, precuneus areas, cerebellum and basal ganglia were consistently activated to a greater extent. In self-priming conditions, the superior frontal gyrus, post-central gyrus, and cingulate gyrus were activated. Comparatively, in cuepriming conditions, the temporal cortex, anterior lobe, precentral gyrus, inferior frontal gyrus and lingual gyrus appeared to be activated.

\section{Comparisons Between the PD and HC Groups in Self-Priming Conditions}

In self-priming conditions, a comparison of activation in relevant brain regions during FTT performance in 135 PD patients and $112 \mathrm{HC}$ participants in eight experiments revealed 55 activation points with greater activation in the PD group than in the $\mathrm{HC}$ group (Figure 4). We discovered 14 clusters of activation, which were located on both sides of the cingulate gyrus, inferior parietal lobule, post-central gyrus, and cerebellar folia IV; the right side of the middle frontal gyrus, inferior frontal gyrus, cerebellar folia II, and central lobule; and the left side of the superior frontal gyrus and cerebellar tonsils (Table 4).

Under the same conditions, 60 activation points in which $\mathrm{HC}$ activation was greater than PD activation were obtained (Figure 5).

We discovered 24 clusters of activation, which were located on both sides of the insula cortex, lentiform nucleus, medial frontal gyrus, superior temporal gyrus, anterior cingulate cortex, superior frontal gyrus, caudate nucleus, and precentral gyrus; the right side of the thalamus, superior parietal lobule, and precuneus; and the left side of the transverse temporal gyrus, mediodorsal thalamic nucleus, and medial geniculate nucleus (Table 5).

\section{Comparisons Between the PD and HC Groups in Cue-Priming Conditions}

In cue-priming conditions, a comparison of activation in relevant brain regions during FTT performance in 11 PD patients and 67 HC participants revealed 51 points with greater activation in the PD than in the HC group (Figure 6). We found three clusters 

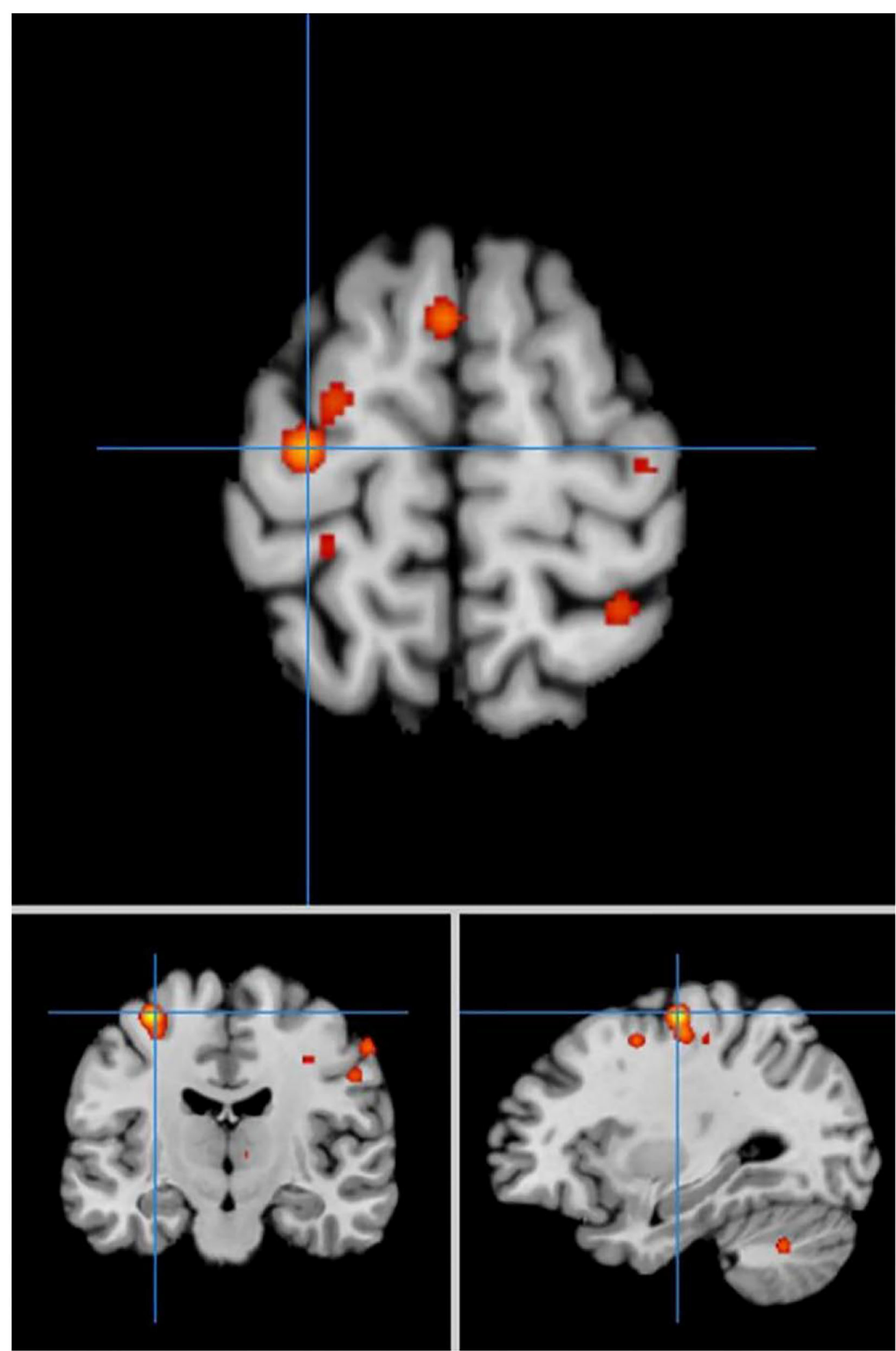

FIGURE 4 | Significant clusters with PD > HC activation in the ALE meta-analysis in self-priming conditions. 
TABLE 4 | Clusters with PD > HC activation in cue-priming conditions.

\begin{tabular}{|c|c|c|c|c|c|c|c|}
\hline Activation cluster & & omical region & BA area & $\mathbf{x}$ & $\mathbf{y}$ & $\mathbf{z}$ & ALE \\
\hline$\# 1$ & $\mathrm{~L}$ & Superior frontal gyrus & BA 8 & -24 & 46 & 40 & 0.006917 \\
\hline \#2 & $\mathrm{R}$ & Inferior frontal gyrus & BA 9 & 48 & 14 & 20 & 0.006966 \\
\hline \#3 & $\mathrm{R}$ & Middle frontal gyrus & BA 6 & 42 & 6 & 38 & 0.007347 \\
\hline \#4 & $\mathrm{R}$ & Cingulate gyrus & BA 32 & 18 & 30 & 28 & 0.008065 \\
\hline \#5 & $\mathrm{L}$ & Cingulate gyrus & BA 31 & 0 & -44 & 36 & 0.007086 \\
\hline \#6 & $\mathrm{R}$ & Inferior parietal lobule & BA 40 & 40 & -36 & 40 & 0.008692 \\
\hline \#7 & $L$ & Inferior parietal lobule & BA 40 & -36 & -40 & 50 & 0.008392 \\
\hline \#8 & $\mathrm{L}$ & Cerebellar tonsils & & -30 & -60 & -38 & 0.007565 \\
\hline$\# 9$ & $\mathrm{R}$ & Cerebellar folia II & & 36 & -28 & 10 & 0.007137 \\
\hline \#10 & $\mathrm{R}$ & Cerebellar folia IV & & 20 & -68 & 44 & 0.008056 \\
\hline \#11 & $L$ & Cerebellar folia IV & & -24 & -48 & 56 & 0.006941 \\
\hline$\# 12$ & $\mathrm{R}$ & Post-central gyrus & BA 2 & 40 & -20 & 58 & 0.007579 \\
\hline \#13 & $\mathrm{L}$ & Post-central gyrus & BA 5 & -26 & -36 & 66 & 0.00833 \\
\hline \#14 & $\mathrm{R}$ & Central lobule & BA 2 & 54 & -14 & 34 & 0.007111 \\
\hline
\end{tabular}

of activation, which were located on the left side of the superior frontal gyrus, inferior frontal gyrus, and superior temporal gyrus (Table 6).

In cue-priming conditions, a comparison of activation in relevant brain regions during FTT performance in $11 \mathrm{PD}$ patients and $67 \mathrm{HC}$ participants revealed 15 points with greater activation in the HC group than in the PD group (Figure 7). We found 9 clusters of activation, which were located on the right side of the lentiform nucleus, claustrum nucleus, and middle frontal gyrus and on the left side of the medial frontal gyrus, thalamus, superior parietal lobule, caudate nucleus, inferior parietal lobule, and cerebellar folia II (Table 7).

\section{DISCUSSION}

\section{Neural Basis of Motor Executive Control in PD Patients During FTT Performance}

The results of the present study demonstrated that during the FTT, the PD patients had a wide range of activated regions, including the middle frontal gyrus, precentral gyrus, post-central gyrus, superior parietal lobe, inferior parietal lobule, cerebellum, and basal ganglia. These results are in line with previous studies showing that when PD patients perform the FTT, brain regions associated with motor task performance, such as the primary sensorimotor cortex, supplementary motor area, basal ganglia and cerebellum, are activated (Witt et al., 2008; Liberg et al., 2013; Ruppert et al., 2020). The primary sensorimotor cortex is the key executive center not only for voluntary movements (Gerloff et al., 1998) but also for complex sequential tapping tasks (Wessel et al., 1997; Kawashima et al., 1999). The supplementary motor area has been considered essential for essential for simple autonomic movement and has also been associated with more advanced motor processing functions (Disbrow et al., 2013). Activation in the basal ganglia has been associated with simple and more complex repetitive movements (Nagano-Saito et al., 2014). In addition, regions in the cerebellum have been found to be involved in the preparation, execution, and timing of both simple and complex movements (Habas et al., 2004; Niethammer et al., 2012).

In self-priming conditions, the cingulate gyrus (BA32), inferential parietal lobule and post-central gyrus (BA2) were specifically activated in the PD patients. The cingulate gyrus has been shown to play a role in sclerometer regulation and response selection (Devinsky et al., 1995). The anterior cingulate cortex (BA24) has been associated with the somatomotor and somatosensory areas and plays a key role in attention allocation (Pardo et al., 1990; Kondo et al., 2004). In selfpriming conditions, more continuous attention and movement are needed, thus activating important brain regions involved in the regulation of attention and movements, such as the cingulate gyrus and post central gyrus.

In cue-priming conditions, $\mathrm{PD}$ patients showed specific activations in the lingual gyrus, inferior frontal gyrus, anterior lobe, and precentral gyrus (BA4). The visual cortex is located in the lingual gyrus, which is used to detect and process visual information related to motor execution (Zeki et al., 1991; Machielsen et al., 2000; Disbrow et al., 2013); thus, it is activated to a greater extent in cue-priming conditions. The inferior frontal gyrus has been associated with finger movements (Harrington et al., 2000) and motor learning (Seitz and Roland, 1992) and participates in the inhibitory control of motor responses (Ramsey et al., 1996). The precentral gyrus is also known as the motor strip or primary motor cortex, which is mainly responsible for executing voluntary movements (Burciu and Vaillancourt, 2018). The anterior lobe of the cerebellum receives information associated with executive function from the dorsolateral prefrontal cortex and posterior parietal lobes (Drucker et al., 2019).

In summary, FTT performance activates a wide range of brain regions involved in motor executive control. The frontal cortex of the brain showed the most activation, suggesting that it may act as the core region in finger-tapping movement. The frontal lobe of the brain is the core brain region of executive control (Zhang et al., 2017), indicating that executive control function plays a key role in FTT performance in individuals with PD. 

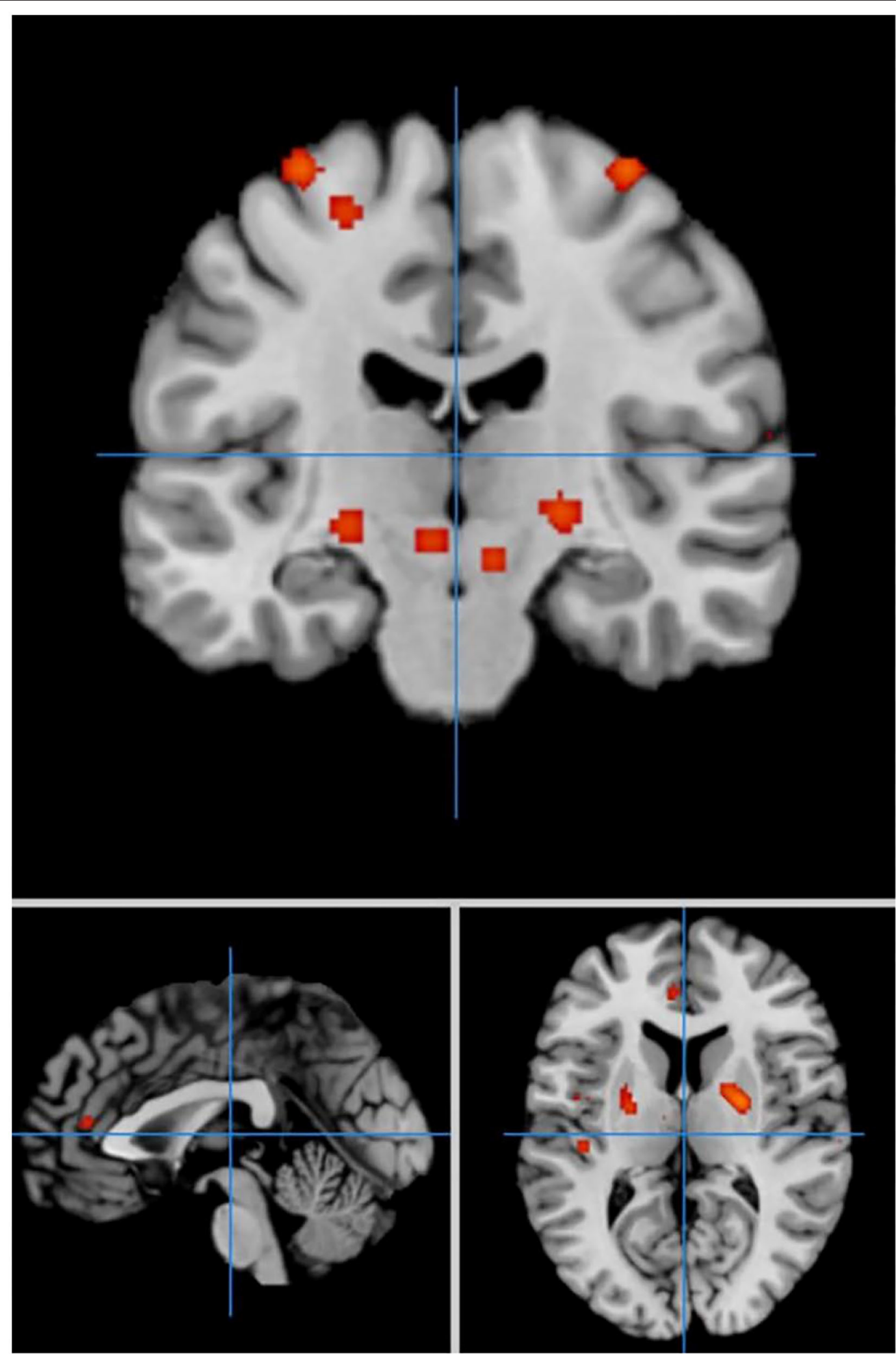

FIGURE 5 | Significant clusters with HC > PD activation in the ALE meta-analysis in self-priming conditions. 
TABLE 5 | Clusters with $\mathrm{HC}>$ PD activation in cue-priming conditions.

\begin{tabular}{|c|c|c|c|c|c|c|c|}
\hline Activation cluster & & Anatomical region & BA area & $\mathbf{x}$ & $\mathbf{y}$ & $\mathbf{z}$ & ALE \\
\hline$\# 1$ & $\mathrm{R}$ & Insula cortex & & 44 & -10 & -2 & 0.007161 \\
\hline \#2 & $L$ & Insula cortex & 13 & -40 & -4 & 12 & 0.007682 \\
\hline \#3 & $\mathrm{R}$ & Lentiform nucleus & & 30 & 0 & -10 & 0.011021 \\
\hline \#4 & $\mathrm{L}$ & Lentiform nucleus & & -22 & -8 & 10 & 0.007789 \\
\hline \#5 & $\mathrm{L}$ & Transverse temporal gyrus & 41 & -42 & -24 & 10 & 0.007331 \\
\hline \#6 & $\mathrm{R}$ & Red nucleus brainstem & & 8 & -20 & -14 & 0.00804 \\
\hline$\# 7$ & $\mathrm{~L}$ & Red nucleus brainstem & & -6 & -20 & -10 & 0.007914 \\
\hline \#8 & $\mathrm{R}$ & Medial frontal gyrus & 6 & 12 & 2 & 58 & 0.008337 \\
\hline$\# 9$ & $L$ & Medial frontal gyrus & 6 & -10 & 12 & 50 & 0.008341 \\
\hline \#10 & $\mathrm{R}$ & Superior temporal gyrus & 42 & 66 & -22 & 12 & 0.008037 \\
\hline \#11 & $\mathrm{L}$ & Superior temporal gyrus & 38 & -42 & 4 & -24 & 0.00743 \\
\hline$\# 12$ & $\mathrm{R}$ & Anterior cingulate cortex & 24 & 12 & 30 & -12 & 0.00717 \\
\hline \#13 & $\mathrm{L}$ & Anterior cingulate cortex & 32 & -6 & 40 & 12 & 0.010476 \\
\hline \#14 & $\mathrm{R}$ & Thalamus & & 22 & -18 & -4 & 0.007713 \\
\hline \#15 & $\mathrm{L}$ & Mediodorsal thalamic nucleus & & -8 & -12 & 4 & 0.008039 \\
\hline \#16 & $\mathrm{L}$ & Medial geniculate nucleus & & -14 & -28 & -8 & 0.007689 \\
\hline \#17 & $R$ & Superior parietal lobule & 7 & 42 & -57 & 60 & 0.008697 \\
\hline \#18 & $\mathrm{R}$ & Superior frontal gyrus & 9 & 42 & 48 & 28 & 0.014485 \\
\hline \#19 & $L$ & Superior frontal gyrus & 9 & -40 & 50 & 26 & 0.01132 \\
\hline \#20 & $\mathrm{R}$ & Caudate nucleus & & 16 & 0 & 16 & 0.009735 \\
\hline \#21 & $L$ & Caudate nucleus & & -14 & 6 & 18 & 0.008467 \\
\hline \#22 & $\mathrm{R}$ & Precuneus & 7 & 10 & -72 & 52 & 0.007176 \\
\hline \#23 & $\mathrm{R}$ & Pre-central gyrus & 4 & 30 & -14 & 50 & 0.007702 \\
\hline \#24 & $\mathrm{L}$ & Pre-central gyrus & 4 & -32 & -18 & 68 & 0.008502 \\
\hline
\end{tabular}

\section{Brain Activation Contrasts Between PD Patients and HCs in Self-Priming Conditions}

In self-priming conditions, the PD patients showed more activation in the frontal lobe areas, inferior parietal lobule and cerebellum than the HC participants. In the HC groups, the activation in the superior parietal lobule, insula cortex and basal ganglia was more significant.

A great deal of evidence suggests that the coordination of goaldriven behavior is supported by the frontoparietal network (FPN) (He et al., 2007; Marek and Dosenbach, 2018). The dorsolateral pre-frontal cortex (BA 9) and ventrolateral pre-frontal cortex (BA 45 ) are involved in regulating movement and behavior through inhibitory control. The parietal cortex plays a role in selecting and monitoring motion sequences (Deiber et al., 1991). It is involved in time perception of motion sequences to ensure that each movement occurs after the successful completion of the previous movement (Sirigu et al., 1996; Macar et al., 2002; Bueti and Walsh, 2009). The cerebral cortex, which includes areas such as the pre-frontal and parietal cortices, the dorsal cingulate cortex and the insula, may constitute a reactive inhibition pathway, playing a role in inhibitory control (Macar et al., 2002; Meyer and Bucci, 2016).

In self-priming conditions, the PD patients showed activation in the cerebellum, including the central lobule, cerebellar folia II, cerebellar folia VI and cerebellar tonsils. The mechanisms underlying the wide range of activation in cerebellar areas remain unclear. It is possible that activation of some specific cerebellar areas compensates for impaired basal ganglia function in PD patients (Kübel et al., 2018). The activity of cerebellum was increased during automated movements, which may reflect compensatory function of cerebellum. The activation of the supplementary motor area (including the promoter cortex and the association area) in PD patients is relatively insufficient in self-priming conditions. It is possible that this region is a key brain region for initiating movement, especially for internally generated voluntary movement (Tanji and Hoshi, 2001; Disbrow et al., 2013). Insufficient activation of the supplementary motor area may also contribute to deficits in timing and generating movements (Simmonds et al., 2008; Jacobs et al., 2009).

In self-priming conditions, the regions that were more activated in HCs reflect the pathological structural regions in PD patients. These areas are also important targets for the development of interventions for PD treatment "or" for the development of interventions or PD treatment (e.g., exercisebased interventions). The lentiform nucleus and the caudate nucleus within the basal ganglia are widely acknowledged as key sites of PD pathology (Albani et al., 2001). The thalamus acts as the central relay station of the brain, filtering and transmitting sensory input to the cerebral cortex, and is a key node in the cerebellum-thalamus-prefrontal cortex pathway (Jech et al., 2012). The parietal lobe is an important sensory area that is 

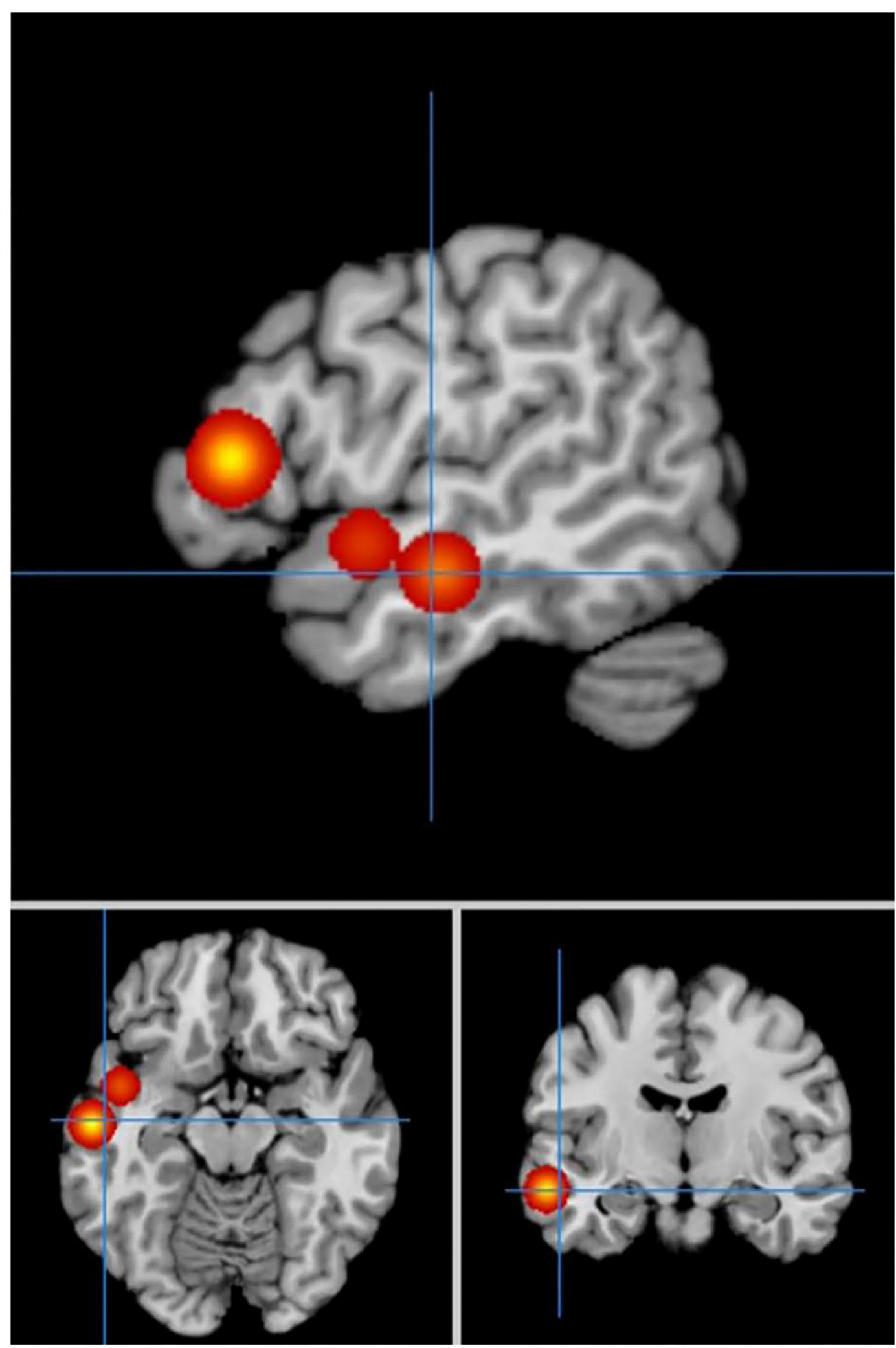

FIGURE 6 | Significant clusters with PD > HC activation in the ALE meta-analysis in cue-priming conditions. 
TABLE 6 | Clusters with PD > HC activation in cue-priming conditions.

\begin{tabular}{|c|c|c|c|c|c|c|c|}
\hline Activation cluster & & tomical region & BA area & $\mathbf{x}$ & $y$ & $\mathbf{z}$ & ALE \\
\hline$\# 1$ & $\mathrm{~L}$ & Superior frontal gyrus & BA 39 & -20 & 62 & 20 & 0.006901 \\
\hline \#2 & $\mathrm{L}$ & Inferior frontal gyrus & BA 46 & -52 & 30 & 8 & 0.006901 \\
\hline \#3 & $\mathrm{L}$ & Superior temporal gyrus & BA 38 & -52 & -6 & -13 & 0.000357 \\
\hline
\end{tabular}

associated with executive function. Insufficient activation or reduced connectivity in these areas may result in decreased motor executive control function and even motor impairment in PD patients (Tinaz et al., 2016). When PD patients perform selfpriming exercises, not only the frontal lobe and parietal lobe show abnormal activities but also the interactions within the motor network are disrupted. The reduction in psychomotor functional connectivity (especially in cortico-basal ganglia and basal ganglia-cerebellum loops) may lead to impairments in automatic movements in PD patients (Palomar et al., 2013; Smittenaar et al., 2013). PD patients may need to increase connectivity within the cortico-cerebellum loop to compensate for the dysfunction of the basal ganglia to properly perform the task in the self-priming condition.

\section{Brain Activation Contrasts Between PD Patients and HCs in Cue-Priming Conditions}

In cue-priming conditions, the PD patients showed more activation on the left side in the superior frontal gyrus, inferior frontal gyrus, and superior temporal gyrus. In the HCs, activation in the cerebellum, thalamus, caudate nucleus, superior parietal lobule, inferior parietal lobule, right middle frontal gyrus, insula cortex and basal ganglia was more significant.

When the FTT was performed with external cues, the PD patients needed to coordinate finger movements with the external stimulus signals. In cue-priming conditions, the superior frontal gyrus and superior temporal gyrus in PD patients showed greater activation. These activations may reflect compensatory mechanisms. Past studies have shown that the cortical-striatothalamic-cortical circuit is a key loop for motor initiation and inhibition and maintains the balance between activation and inhibition in the motor circuit (Hacker et al., 2012; Peters et al., 2016). External cues may enhance the input of the frontal region in the executive and inhibitory functions related to motor tasks in PD patients, thus compensating for the functional deficits of the basal ganglia in the selection and execution of motor tasks and improving the imbalance of activation and inhibition circuits.

The parietal lobe plays an important role in sensorymotor transformation and visual guidance of movement (Wu and Hallett, 2005). The posterior parietal cortex is associated with motoring highly integrated tasks, including task switching, visually guided motor planning, and attentional control (Macaluso et al., 2000; Liston et al., 2006). Insufficient activation in the parietal lobes of PD patients leads to impaired functions in motor planning. However, external cues may mobilize the activation of the visual area of the superior temporal gyrus, which is also involved in motor executive control, and thus, improve motor performance in PD patients (Vikene et al., 2019). This result indicates that in addition to the parietal lobe. Other brain regions within sensory pathways may have similar functions.

The activation levels in the cerebellar regions, especially in the cerebellar folia II, were lower in the PD group than in the HC group under cue-priming conditions. This result is consistent with previous studies on bimanual tasks (Islam et al., 2011) and the viscometric predictive tracking task in PD patients (Turner et al., 2003). Interactively in the cerebellar areas may imply that PD patients have difficulty achieving sensorimotor integration of finger movements with external stimulus signals (Jueptner and Weiller, 1998; van Donkelaar et al., 2000; Lewis et al., 2013). However, some studies have reported over-activation in the cerebellum in PD patients during cue-priming FTT and thumb pressing (Mak et al., 2016). Due to the limited numbers of studies examining cue-priming conditions included in the current metaanalysis, how external cues impact the function of cerebellar regions needs further investigation. Increasing evidence has shown that the role of the cerebellum in PD is complicated (Strick et al., 2005; Bostan et al., 2010; Stoodley et al., 2012). Different areas of the cerebellum may show different responses to stimulation and action execution.

\section{STRENGTH AND LIMITATIONS}

The present study provides a quantitative summary of past imaging studies with the FTT in PD patients, with a focus on the impact of the priming condition on the distribution of activation across brain regions. The study demonstrates that the two priming conditions yield some divergence in areas activated in PD patients. The cue-priming manipulation alters the brain regions that are activated and its functional expression during motor execution. It is worth discussing the potential influence of external cues on motor executive control in PD patients. In cue-priming conditions, brain activity in regions associated with perceptual processing and inhibitory control was enhanced. The results of the current study provide a neuropathological basis for using external cues in motor executive training in treating mild to moderate PD.

The present study has several limitations. First, although coordinate-based meta-analyses (CBMA), such as ALE, can assess whether the convergence between reported coordinates in the brain is statistically higher (Eickhoff et al., 2012), they cannot explain whether the activated coordinates are a direct result of the task itself or whether the brain regions are functionally coupled with other regions. To investigate the effective connectivity of brain regions, future studies can adopt methods such as the 

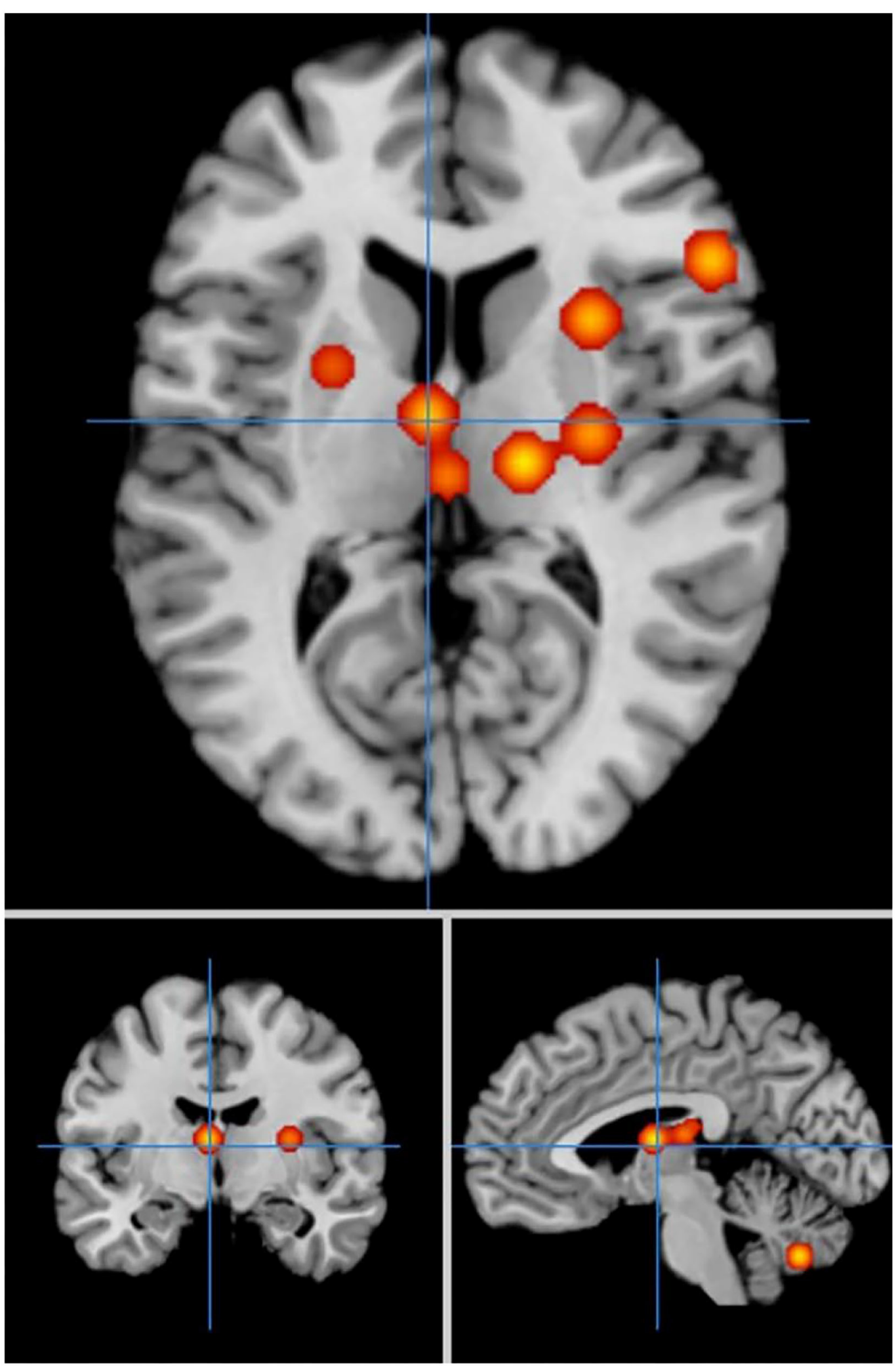

FIGURE 7 | Significant clusters with HC > PD activation in the ALE meta-analysis in cue-priming conditions. 
TABLE 7 | Clusters with $\mathrm{HC}>$ PD activation in cue-priming conditions.

\begin{tabular}{|c|c|c|c|c|c|c|c|}
\hline Activation cluster & & tomical region & BA area & $\mathbf{x}$ & $\mathbf{y}$ & $\mathbf{z}$ & ALE \\
\hline$\# 1$ & $\mathrm{R}$ & Lentiform nucleus & & 30 & -12 & 10 & 0.006906 \\
\hline \#2 & $\mathrm{R}$ & Middle frontal gyrus & BA 9 & 46 & 34 & 24 & 0.006849 \\
\hline \#3 & $\mathrm{R}$ & Claustrum nucleus & & 30 & 12 & 7 & 0.006901 \\
\hline \#4 & $\mathrm{L}$ & Medial frontal gyrus & BA 6 & -18 & 0 & 55 & 0.007787 \\
\hline \#5 & $\mathrm{L}$ & Thalamus & & -4 & -8 & 10 & 0.008051 \\
\hline \#6 & $\mathrm{L}$ & Superior parietal lobule & BA 7 & -26 & -54 & 50 & 0.007061 \\
\hline \#7 & $L$ & Caudate nucleus & & -16 & 8 & 20 & 0.008101 \\
\hline \#8 & $\mathrm{L}$ & Inferior parietal lobule & BA 40 & -62 & -40 & 28 & 0.008037 \\
\hline$\# 9$ & $\mathrm{~L}$ & Cerebellar folia II & & -6 & -69 & -39 & 0.008407 \\
\hline
\end{tabular}

dynamic causal model (DCM) (Stephan et al., 2007). Second, only 15 studies (with 160 foci), which had small sample sizes, fulfilled the inclusion criteria and were included in the ALE metaanalysis. This limitation may have reduced the power of the analysis (Eickhoff et al., 2016). Future work with larger samples is needed to develop better interpretations of activated regions during FTT performance in PD patients. In addition, due to a lack of research evaluating cue-priming conditions with the FTT in clinical studies, this meta-analysis simply distinguished the experimental conditions into self-priming and cue-priming. With an increase in the number of relevant studies, future metaanalyses can refine the attributes of priming conditions (e.g., visual, auditory, tactile) or a combination of these sensory cues to examine the brain activation of motor executive control in $\mathrm{PD}$ patients.

\section{CONCLUSION}

In summary, using ALE meta-analysis, this study found that there was significant activation in the middle frontal gyrus, precentral gyrus, post-central gyrus, superior parietal lobe, inferior parietal lobule, cerebellum, and basal ganglia during FTT performance in PD patients. In self-priming conditions, PD patients had less activation in the parietal lobe and insular cortex than the HCs, however, cerebellar areas were overactivated. In cue-priming conditions, the cerebellum and frontal-parietal areas were less activated, and the superior frontal gyrus and superior temporal gyrus were overactivated in PD patients. Our study illustrates that the cue-priming manipulation affects the distribution of activity in brain regions involved in motor control and motor performance in PD patients. In cue-priming conditions, brain activity in regions associated with perceptual processing and

\section{REFERENCES}

Acar, F., Seurinck, R., Eickhoff, S. B., and Moerkerke, B. (2018). Assessing robustness against potential publication bias in Activation Likelihood Estimation (ALE) meta-analyses for fMRI. PLoS ONE 13:e0208177. doi: 10.1371/journal.pone. 0208177 inhibitory control was enhanced. The sensory motor areas associated with attention and motor control were impaired. In the design of future interventions for PD and other clinical movement disorders, cue-priming manipulations can be utilized in designing interventions (e.g., exercise-based interventions) for PD patients.

\section{DATA AVAILABILITY STATEMENT}

The original contributions presented in the study are included in the article/supplementary material, further inquiries can be directed to the corresponding author.

\section{AUTHOR CONTRIBUTIONS}

XX contributed to the supervision of the meta-analysis and provided the methodology expertise. JL conceptualized the project, organized the study selection, data extraction, performed the data analysis, and visualized the results. $\mathrm{ZL}$ and $\mathrm{ZD}$ contributed to the critical review of relevant literature. NZ and XQ contributed to the selection and coding procedures. JL, $\mathrm{ZL}$, and $\mathrm{ZD}$ contributed to the discussion of the results and drafting of the final manuscript. All authors critically revised the manuscript and approved the final version.

\section{FUNDING}

This research was supported by National Natural Science Foundation of China (Grant no. 81971661), Hubei Superior Discipline Group of Exercise and Brain Science from Hubei Provincial Department of Education. 
Bologna, M., Leodori, G., Stirpe, P., Paparella, G., Colella, D., Belvisi, D., et al. (2016). Bradykinesia in early and advanced Parkinson's disease. J. Neurol. Sci. 369, 286-291. doi: 10.1016/j.jns.2016.08.028

Bostan, A. C., Dum, R. P., and Strick, P. L. (2010). The basal ganglia communicate with the cerebellum. Proc. Natl. Acad. Sci. U.S.A. 107, 8452-8456. doi: 10.1073/pnas.1000496107

Bueti, D., and Walsh, V. (2009). The parietal cortex and the representation of time, space, number and other magnitudes. Philos. Trans. Biol. Sci. 364, 1831-1840. doi: $10.1098 /$ rstb. 2009.0028

Burciu, R. G., and Vaillancourt, D. E. (2018). Imaging of motor cortex physiology in Parkinson's disease. Movement Disord. 33, 1688-1699. doi: 10.1002/mds.102

*Cerasa, A., Hagberg, G. E., Peppe, A., Bianciardi, M., Gioia, M. C., Costa, A., et al. (2006). Functional changes in the activity of cerebellum and frontostriatal regions during externally and internally timed movement in Parkinson's disease. Brain Res. Bull. 71, 259-269. doi: 10.1016/j.brainresbull.2006.09.014

Deiber, M., Passingham, R., Colebatch, J., Friston, K., Nixon, P., and Frackowiak, R. (1991). Cortical areas and the selection of movement: a study with positron emission tomography. Exp. Brain Res. 84, 393-402.

del Olmo, M. F., Arias, P., Furio, M., Pozo, M., and Cudeiro, J. (2006). Evaluation of the effect of training using auditory stimulation on rhythmic movement in Parkinsonian patients-a combined motor and [18F]-FDG PET study. Parkinsonism Related Disord. 12, 155-164. doi: 10.1016/j.parkreldis.2005.11.002

Devinsky, O., Morrell, M. J., and Vogt, B. A. (1995). Contributions of anterior cingulate cortex to behaviour. Brain 118( $\mathrm{Pt} 1), 279-306$. doi: 10.1093/brain/118.1.279

*Disbrow, E. A., Sigvardt, K. A., Franz, E. A., Turner, R. S., Russo, K. A., Hinkley, L. B., et al. (2013). Movement activation and inhibition in Parkinson's disease: a functional imaging study. J. Parkinson's Dis. 3, 181-192. doi: $10.3233 /$ jpd-130181

Drucker, J. H., Sathian, K., Crosson, B., Krishnamurthy, V., McGregor, K. M., Bozzorg, A., et al. (2019). Internally guided lower limb movement recruits compensatory cerebellar activity in people with Parkinson's disease. Front. Neurol. 10, 537-537. doi: 10.3389/fneur.2019.00537

Eickhoff, S. B., Bzdok, D., Laird, A. R., Kurth, F., and Fox, P. T. (2012). Activation likelihood estimation meta-analysis revisited. NeuroImage 59, 2349-2361. doi: 10.1016/j.neuroimage.2011.09.017

Eickhoff, S. B., Nichols, T. E., Laird, A. R., Hoffstaedter, F., Amunts, K., Fox, P. T., et al. (2016). Behavior, sensitivity, and power of activation likelihood estimation characterized by massive empirical simulation. NeuroImage 137, 70-85. doi: 10.1016/j.neuroimage.2016.04.072

Elbaz, A., Carcaillon, L., Kab, S., and Moisan, F. (2016). Epidemiology of Parkinson's disease. Revue Neurol. 172, 14-26. doi: 10.1016/j.neurol.2015.09.012

Georgiou, N., Bradshaw, J. L., Iansek, R., Phillips, J. G., Mattingley, J. B., and Bradshaw, J. A. (1994). Reduction in external cues and movement sequencing in Parkinson's disease. J. Neurol. Neurosurgery Psychiatry 57, 368-370. doi: 10.1136/jnnp.57.3.368

Gerloff, C., Corwell, B., Chen, R., Hallett, M., and Cohen, L. G. (1998). The role of the human motor cortex in the control of complex and simple finger movement sequences. Brain 121(Pt 9), 1695-1709. doi: 10.1093/brain/121.9.1695

Goetz, C. G. (2011). The history of Parkinson's disease: early clinical descriptions and neurological therapies. Cold Spring Harbor Persp. Med. 1:a008862. doi: $10.1101 /$ cshperspect.a008862

Golden, C. J., Espe-Pfeifer, P., and Wachsler-Felder, J. (2002). Neuropsychological Interpretation of Objective Psychological Tests. New York, NY; Boston, MA: Springer US. doi: 10.1007/b107998

*González-García, N., Armony, J. L., Soto, J., Trejo, D., Alegría, M. A., and Drucker-Colín, R. (2011). Effects of rTMS on Parkinson's disease: a longitudinal fMRI study. J. Neurol. 258, 1268-1280. doi: 10.1007/s00415-011-5923-2

Gottlieb, J., and Oudeyer, P.-Y. (2018). Towards a neuroscience of active sampling and curiosity. Neuroscience 19, 758-770. doi: 10.1038/s41583-018-0078-0

Habas, C., Axelrad, H., and Cabanis, E. A. (2004). The cerebellar second homunculus remains silent during passive bimanual movements. Neuroreport 15, 1571-1574. doi: 10.1097/01.wnr.0000133970.53139.e3

Hacker, C. D., Perlmutter, J. S., Criswell, S. R., Ances, B. M., and Snyder, A. Z. (2012). Resting state functional connectivity of the striatum in Parkinson's disease. Brain 135(Pt 12), 3699-3711. doi: 10.1093/brain/aws281
Hackney, M. E., Lee, H. L., Battisto, J., Crosson, B., and McGregor, K. M. (2015). Context-dependent neural activation: internally and externally guided rhythmic lower limb movement in individuals with and without neurodegenerative disease. Front Neurol 6:251. doi: 10.3389/fneur.2015.00251

Harrington, D. L., Rao, S. M., Haaland, K. Y., Bobholz, J. A., Mayer, A. R., Binderx, J. R., et al. (2000). Specialized neural systems underlying representations of sequential movements. J. Cogn. Neurosci. 12, 56-77. doi: 10.1162/08989290051137602

He, B. J., Snyder, A. Z., Vincent, J. L., Epstein, A., Shulman, G. L., and Corbetta, M. (2007). Breakdown of functional connectivity in frontoparietal networks underlies behavioral deficits in spatial neglect. Neuron 53, 905-918. doi: 10.1016/j.neuron.2007.02.013

Helme, R. (1987). Parkinson's disease: recent developments in Parkinson's disease. Med. J. Australia 147, 304-304. doi: 10.5694/j.1326-5377.1987.tb133481.x

Hirano, S. (2021). Clinical implications for dopaminergic and functional neuroimage research in cognitive symptoms of Parkinson's disease. Mol. Med. 27, 40-40. doi: 10.1186/s10020-021-00301-7

Hirtz, D., Thurman, D. J., Gwinn-Hardy, K., Mohamed, M., Chaudhuri, A. R., and Zalutsky, R. (2007). How common are the "common" neurologic disorders? Neurology 68, 326-337. doi: 10.1212/01.wnl.0000252807.38124.a3

Hoehn, M. M., and Yahr, M. D. (1967). Parkinsonism. Neurology 17:427. doi: 10.1212/WNL.17.5.427

*Hughes, L. E., Barker, R. A., Owen, A. M., and Rowe, J. B. (2010). Parkinson's disease and healthy aging: independent and interacting effects on action selection. Human Brain Mapping 31, 1886-1899. doi: 10.1002/hbm.20979

Islam, M., Gordon, A. M., Sköld, A., Forssberg, H., and Eliasson, A. C. (2011). Grip force coordination during bimanual tasks in unilateral cerebral palsy. Dev. Med. Child Neurol. 53, 920-926. doi: 10.1111/j.1469-8749.2011.04040.x

Jacobs, J. V., Lou, J. S., Kraakevik, J. A., and Horak, F. B. (2009). The supplementary motor area contributes to the timing of the anticipatory postural adjustment during step initiation in participants with and without Parkinson's disease. Neuroscience 164, 877-885. doi: 10.1016/j.neuroscience.2009.08.002

Jancke, L., Steinmetz, H., Benilow, S., and Ziemann, U. (2004). Slowing fastest finger movements of the dominant hand with low-frequency rTMS of the hand area of the primary motor cortex. Exp. Brain Res. 155, 196-203. doi: 10.1007/s00221-003-1719-7

Jech, R., Mueller, K., Urgošík, D., Sieger, T., Holiga, Š., RuŽička, F., et al. (2012). The subthalamic microlesion story in Parkinson's disease: electrode insertion-related motor improvement with relative cortico-subcortical hypoactivation in fMRI. PLoS ONE 7:e49056. doi: 10.1371/journal.pone. 0049056

*Jia, Q., Gao, L., Zhang, J., Wu, T., and Chan, P. (2018). Altered functional connectivity of the subthalamic nucleus during selfinitiated movement in Parkinson's disease. J. Neuroradiol. 45, 249-255. doi: 10.1016/j.neurad.2017.11.008

Jueptner, M., and Weiller, C. (1998). A review of differences between basal ganglia and cerebellar control of movements as revealed by functional imaging studies. Brain 121(Pt 8), 1437-1449. doi: 10.1093/brain/121.8.1437

Kawashima, R., Inoue, K., Sugiura, M., Okada, K., Ogawa, A., and Fukuda, H. (1999). A positron emission tomography study of self-paced finger movements at different frequencies. Neuroscience 92, 107-112. doi: 10.1016/S0306-4522(98)00744-1

Kondo, H., Osaka, N., and Osaka, M. (2004). Cooperation of the anterior cingulate cortex and dorsolateral prefrontal cortex for attention shifting. Neuroimage 23, 670-679. doi: 10.1016/j.neuroimage.2004.06.014

Kübel, S., Stegmayer, K., Vanbellingen, T., Walther, S., and Bohlhalter, S. (2018). Deficient supplementary motor area at rest: neural basis of limb kinetic deficits in Parkinson's disease. Hum. Brain Mapp. 39, 3691-3700. doi: 10.1002/hbm.24204

Laird, A. R., Eickhoff, S. B., Kurth, F., Fox, P. M., Uecker, A. M., Turner, J. A., et al. (2009). ALE meta-analysis workflows via the brainmap database: progress towards a probabilistic functional brain Atlas. Front. Neuroinf. 3, 23-23. doi: 10.3389/neuro.11.023.2009

Laird, A. R., Robinson, J. L., McMillan, K. M., Tordesillas-Gutiérrez, D., Moran, S. T., Gonzales, S. M., et al. (2010). Comparison of the disparity between Talairach and MNI coordinates in functional neuroimaging data: validation of the Lancaster transform. NeuroImage 51, 677-683. doi: 10.1016/j.neuroimage.2010.02.048 
Lancaster, J. L., Tordesillas-Gutiérrez, D., Martinez, M., Salinas, F., Evans, A., Zilles, K., et al. (2007). Bias between MNI and Talairach coordinates analyzed using the ICBM-152 brain template. Hum. Brain Mapp. 28, 1194-1205. doi: $10.1002 / \mathrm{hbm} .20345$

Lee, M. S., Lyoo, C. H., Lee, M. J., Sim, J., Cho, H., and Choi, Y. H. (2010). Impaired finger dexterity in patients with parkinson's disease correlates with discriminative cutaneous sensory dysfunction. Mov. Disord. 25, 2531-2535. doi: $10.1002 / \mathrm{mds} .23304$

Levit-Binnun, N., Handzy, N. Z., Peled, A., Modai, I., and Moses, E. (2007). Transcranial magnetic stimulation in a finger-tapping task separates motor from timing mechanisms and induces frequency doubling. J. Cognit. Neurosci. 19, 721-733. doi: 10.1162/jocn.2007.19.5.721

Lewis, M. M., Galley, S., Johnson, S., Stevenson, J., Huang, X., and McKeown, M. J. (2013). The role of the cerebellum in the pathophysiology of Parkinson's disease. Canad. J. Neurol. Sci. 40, 299-306. doi: 10.1017/S03171671000 14232

Liberg, B., Adler, M., Jonsson, T., Landén, M., Rahm, C., Wahlund, L. O., et al. (2013). The neural correlates of self-paced finger tapping in bipolar depression with motor retardation. Acta Neuropsychiatr. 25, 43-51. doi: 10.1111/j.1601-5215.2012.00659.x

Lim, I., van Wegen, E., de Goede, C., Deutekom, M., Nieuwboer, A., Willems, A., et al. (2005). Effects of external rhythmical cueing on gait in patients with Parkinson's disease: a systematic review. Clin. Rehabil. 19, 695-713. doi: 10.1191/0269215505cr906oa

Liston, C., Matalon, S., Hare, T. A., Davidson, M. C., and Casey, B. J. (2006). Anterior cingulate and posterior parietal cortices are sensitive to dissociable forms of conflict in a task-switching paradigm. Neuron 50, 643-653. doi: 10.1016/j.neuron.2006.04.015

Macaluso, E., Frith, C. D., and Driver, J. (2000). Modulation of human visual cortex by crossmodal spatial attention. Science 289, 1206-1208. doi: 10.1126/science.289.5482.1206

Macar, F., Lejeune, H., Bonnet, M., Ferrara, A., Pouthas, V., Vidal, F., et al. (2002). Activation of the supplementary motor area and of attentional networks during temporal processing. Exp. Brain Res. 142, 475-485. doi: 10.1007/s00221-001-0953-0

Machielsen, W. C. M., Rombouts, S. A. R. B., Barkhof, F., Scheltens, P., and Witter, M. P. (2000). fMRI of visual encoding: reproducibility of activation. Hum. Brain Mapp. 9, 156-164. doi: 10.1002/(SICI)1097-0193(200003)9:3<156::AID-HBM4>3. $0 . \mathrm{CO} ; 2-\mathrm{Q}$

Mak, M. K., and Hui-Chan, C. W. (2004). Audiovisual cues can enhance sitto-stand in patients with Parkinson's disease. Mov. Disord. 19, 1012-1019. doi: $10.1002 / \mathrm{mds} .20196$

*Mak, M. K. Y., Cheung, V., Ma, S., Lu, Z. L., Wang, D., Lou, W., et al. (2016). Increased cognitive control during execution of finger tap movement in people with Parkinson's disease. J. Parkinson's Dis. 6, 639-650. doi: $10.3233 /$ JPD-160849

Mak, M. K. Y., and Hui-Chan, C. W. Y. (2008). Cued task-specific training is better than exercise in improving sit-to-stand in patients with Parkinson's disease: a randomized controlled trial. Mov. Disord. 23, 501-509. doi: 10.1002/mds. 21509

*Mallol, R., Barrós-Loscertales, A., López, M., Belloch, V., Parcet, M. A., and Avila, C. (2007). Compensatory cortical mechanisms in Parkinson's disease evidenced with fMRI during the performance of pre-learned sequential movements. Brain Res. 1147, 265-271. doi: 10.1016/j.brainres.2007. 02.046

Marek, S., and Dosenbach, N. U. F. (2018). The frontoparietal network: function, electrophysiology, and importance of individual precision mapping. Dial. Clin. Neurosci. 20, 133-140. doi: 10.31887/DCNS.2018.20.2/smarek

Marsden, C. D. (1994). Parkinson's disease. J. Neurol. Neurosurg. Psychiatry 57, 672-681. doi: 10.1136/jnnp.57.6.672

*Martin, J. A., Zimmermann, N., Scheef, L., Jankowski, J., Paus, S., Schild, H. H., et al. (2019). Disentangling motor planning and motor execution in unmedicated de novo Parkinson's disease patients: an fMRI study. Neuroimage Clin. 22:101784. doi: 10.1016/j.nicl.2019.101784

Meyer, H. C., and Bucci, D. J. (2016). Neural and behavioral mechanisms of proactive and reactive inhibition. Learning Memory 23, 504-514. doi: $10.1101 / \mathrm{lm} .040501 .115$
Mirdamadi, J. L. (2016). Cerebellar role in Parkinson's disease. J. Neurophysiol. 116, 917-919. doi: 10.1152/jn.01132.2015

Moher, D., Liberati, A., Tetzlaff, J., and Altman, D. G. (2009). Preferred reporting items for systematic reviews and meta-analyses: the PRISMA statement. BMJ 339, e78-336. doi: 10.1136/bmj.b2535

Morris, M. E., Iansek, R., Matyas, T. A., and Summers, J. J. (1994). The pathogenesis of gait hypokinesia in Parkinson's disease. Brain 117, 1169-1181. doi: 10.1093/brain/117.5.1169

Nagano-Saito, A., Martinu, K., and Monchi, O. (2014). Function of basal ganglia in bridging cognitive and motor modules to perform an action. Front. Neurosci. 8:187. doi: 10.3389/fnins.2014.00187

Niethammer, M., Feigin, A., and Eidelberg, D. (2012). Functional neuroimaging in Parkinson's disease. Cold Spring Harbor Persp. Med. 2:a009274. doi: 10.1101/cshperspect.a009274

Pal, P. K., Lee, C. S., Samii, A., Schulzer, M., Stoessl, A. J., Mak, E. K., et al. (2001). Alternating two finger tapping with contralateral activation is an objective measure of clinical severity in Parkinson' $s$ disease and correlates with PET [18 F] -DOPA Ki. Park. Relat. Disord. 7, 305-309. doi: 10.1016/S1353-8020(00)00048-1

Palomar, F. J., Conde, V., Carrillo, F., Fernández-del-Olmo, M., Koch, G., and Mir, P. (2013). Parieto-motor functional connectivity is impaired in Parkinson's disease. Brain Stimul. 6, 147-154. doi: 10.1016/j.brs.2012.03.017

Pardo, J. V., Pardo, P. J., Janer, K. W., and Raichle, M. E. (1990). The anterior cingulate cortex mediates processing selection in the stroop attentional conflict paradigm. Proc. Natl. Acad. Sci. U.S.A. 87, 256-259. doi: 10.1073/pnas.87.1.256

Peters, S. K., Dunlop, K., and Downar, J. (2016). Cortico-striatal-thalamic loop circuits of the salience network: a central pathway in psychiatric disease and treatment. Front. Syst. Neurosci. 10:104. doi: 10.3389/fnsys.2016.00104

Picillo, M., Vincos, G. B., Kern, D. S., Fox, S. H., Lang, A. E., and Fasano, A. (2016). Learning more from finger tapping in Parkinson's disease: up and down from Dyskinesia to Bradykinesia. Mov. Disord. Clin. Pract. 3, 184-187. doi: $10.1002 / \mathrm{mdc} 3.12246$

Poldrack, R. A., Kittur, A., Kalar, D., Miller, E., Seppa, C., Gil, Y., et al. (2011). The cognitive atlas: toward a knowledge foundation for cognitive neuroscience. Front. Neuroinf. 5:17. doi: 10.3389/fninf.2011.00017

Qureshi, N. K., Zhang, B., Liang, Z., Tang, W. C., Pu, L., Cong, F., et al. (2020). Therapeutic benefits of music-based synchronous finger tapping in Parkinson's disease-an fNIRS study protocol for randomized controlled trial in Dalian, China. (functional near-infrared spectroscopy). Trials 21:864. doi: 10.1186/s13063-020-04770-9

Ramsey, N. F., Kirkby, B. S., Van Gelderen, P., Berman, K. F., Duyn, J. H., Frank, J. A., et al. (1996). Functional mapping of human sensorimotor cortex with 3D BOLD fMRI correlates highly with H2(15)O PET rCBF. J. Cereb. Blood Flow Metab. 16, 755-764. doi: 10.1097/00004647-199609000-00001

Raut, R. V., Mitra, A., Snyder, A. Z., and Raichle, M. E. (2019). On time delay estimation and sampling error in resting-state fMRI. NeuroImage 194, 211-227. doi: 10.1016/j.neuroimage.2019.03.020

*Rowe, J., Stephan, K. E., Friston, K., Frackowiak, R., Lees, A., and Passingham, R. (2002). Attention to action in Parkinson's disease: impaired effective connectivity among frontal cortical regions. Brain 125(Pt 2), 276-289. doi: 10.1093/brain/awf036

Ruppert, M. C., Greuel, A., Tahmasian, M., Schwartz, F., Stürmer, S., Maier, F., et al. (2020). Network degeneration in Parkinson's disease: multimodal imaging of nigro-striato-cortical dysfunction. Brain 143, 944-959. doi: 10.1093/brain/awaa019

*Sabatini, U., Boulanouar, K., Fabre, N., Martin, F., Carel, C., Colonnese, C., et al. (2000). Cortical motor reorganization in akinetic patients with Parkinson's disease: a functional MRI study. Brain 123(Pt 2), 394-403. doi: 10.1093/brain/123.2.394

*Samuel, M., Ceballos-Baumann, A. O., Blin, J., Uema, T., Boecker, H., Passingham, R. E., et al. (1997). Evidence for lateral premotor and parietal overactivity in Parkinson's disease during sequential and bimanual movements. A PET study. Brain 120(Pt 6), 963-976. doi: 10.1093/brain/120.6.963

Seitz, R. J., and Roland, P. E. (1992). Learning of sequential finger movements in man: a combined kinematic and Positron Emission Tomography (PET) study. Euro. J. Neurosci. 4, 154-165. doi: 10.1111/j.1460-9568.1992.tb00862.x

Sethi, K. (2008). Levodopa unresponsive symptoms in Parkinson disease. Mov. Disord. 23, S521-S533. doi: 10.1002/mds.22049 
Simmonds, D. J., Pekar, J. J., and Mostofsky, S. H. (2008). Meta-analysis of Go/No-go tasks demonstrating that fMRI activation associated with response inhibition is task-dependent. Neuropsychologia 46, 224-232. doi: 10.1016/j.neuropsychologia.2007.07.015

Sirigu, A., Duhamel, J. R., Cohen, L., Pillon, B., Dubois, B., and Agid, Y. (1996). The mental representation of hand movements after parietal cortex damage. Science 273, 1564-1568. doi: 10.1126/science.273.5281.1564

Smittenaar, P., Guitart-Masip, M., Lutti, A., and Dolan, R. J. (2013). Preparing for selective inhibition within frontostriatal loops. J. Neurosci. 33, 18087-18097. doi: 10.1523/JNEUROSCI.2167-13.2013

Stegemöller, E. L., Uzochukwu, J., Tillman, M. D., McFarland, N. R., Subramony, S. H., Okun, M. S., et al. (2015). Repetitive finger movement performance differs among Parkinson's disease, Progressive Supranuclear Palsy, and spinocerebellar ataxia. J. Clin. Mov. Disord. 2:6. doi: 10.1186/s40734-0140015-y

Stephan, K. E., Harrison, L. M., Kiebel, S. J., David, O., Penny, W. D., and Friston, K. J. (2007). Dynamic causal models of neural system dynamics: current state and future extensions. J. Biosci. 32, 129-144. doi: 10.1007/s12038-0070012-5

Stoodley, C. J., Valera, E. M., and Schmahmann, J. D. (2012). Functional topography of the cerebellum for motor and cognitive tasks: an fMRI study. NeuroImage 59, 1560-1570. doi: 10.1016/j.neuroimage.2011.08.065

Strick, P. L., Carras, P. L., Féger, J., Tremblay, L., and Hoshi, E. (2005). The cerebellum communicates with the basal ganglia. Nat. Neurosci. 8, 1491-1493. doi: $10.1038 / \mathrm{nn} 1544$

Studenka, B. E., and Zelaznik, H. N. (2011). Synchronization in repetitive smooth movement requires perceptible events. Acta Psychol. 136, 432-441. doi: 10.1016/j.actpsy.2011.01.011

Tahmasian, M., Eickhoff, S. B., Giehl, K., Schwartz, F., Herz, D. M., Drzezga, A., et al. (2017). Resting-state functional reorganization in Parkinson's disease: an activation likelihood estimation meta-analysis. Cortex 92, 119-138. doi: 10.1016/j.cortex.2017.03.016

Tanji, J., and Hoshi, E. (2001). Behavioral planning in the prefrontal cortex. Curr. Opin. Neurobiol. 11, 164-170. doi: 10.1016/s0959-4388(00)00192-6

*Tessa, C., Diciotti, S., Lucetti, C., Baldacci, F., Cecchi, P., Giannelli, M., et al. (2013). fMRI changes in cortical activation during task performance with the unaffected hand partially reverse after ropinirole treatment in de novo Parkinson's disease. Parkinsonism Relat. Disord. 19, 265-268. doi: 10.1016/j.parkreldis.2012.07.018

Tinaz, S., Lauro, P., Hallett, M., and Horovitz, S. G. (2016). Deficits in taskset maintenance and execution networks in Parkinson's disease. Brain Struct. Funct. 221, 1413-1425. doi: 10.1007/s00429-014-0981-8

Tolosa, E., Gaig, C., Santamaría, J., and Compta, Y. (2009). Diagnosis and the premotor phase of Parkinson disease. Neurology 72, S12-S20. doi: 10.1212/WNL.0b013e318198db11

Turkeltaub, P. E., Eden, G. F., Jones, K. M., and Zeffiro, T. A. (2002). Meta-analysis of the functional neuroanatomy of single-word reading: method and validation. Neuroimage 16(3 Pt 1), 765-780. doi: 10.1006/nimg.2002.1131

Turkeltaub, P. E., Eickhoff, S. B., Laird, A. R., Fox, M., Wiener, M., and Fox, P. (2012). Minimizing within-experiment and within-group effects in activation likelihood estimation meta-analyses. Human Brain Mapp. 33, 1-13. doi: 10.1002/hbm.21186

Turner, R. S., Grafton, S. T., McIntosh, A. R., DeLong, M. R., and Hoffman, J. M. (2003). The functional anatomy of Parkinsonian bradykinesia. Neuroimage 19, 163-179. doi: 10.1016/s1053-8119(03)00059-4

van Donkelaar, P., Stein, J. F., Passingham, R. E., and Miall, R. C. (2000). Temporary inactivation in the primate motor thalamus during visually triggered and internally generated limb movements. J. Neurophysiol. 83, 2780-2790. doi: 10.1152/jn.2000.83.5.2780

\footnotetext{
*Indicate studies included in the meta-analysis.
}

van Eimeren, T., Wolbers, T., Münchau, A., Büchel, C., Weiller, C., and Siebner, H. R. (2006). Implementation of visuospatial cues in response selection. Neuroimage 29, 286-294. doi: 10.1016/j.neuroimage.2005.07.014

Versaci, L., and Laje, R. (2021). Time-oriented attention improves accuracy in a paced finger tapping task. Euro. J. Neurosci. 54:15245. doi: 10.1111/ejn.15245

Vikene, K., Skeie, G. O., and Specht, K. (2019). Compensatory task-specific hypersensitivity in bilateral planum temporale and right superior temporal gyrus during auditory rhythm and omission processing in Parkinson's disease. Sci. Rep. 9:12623. doi: 10.1038/s41598-019-48791-0

Wessel, K., Zeffiro, T., Toro, C., and Hallett, M. (1997). Self-paced versus metronome-paced finger movements. A positron emission tomography study. J. Neuroimaging 7, 145-151.

Witt, S. T., Laird, A. R., and Meyerand, M. E. (2008). Functional neuroimaging correlates of finger-tapping task variations: an ALE meta-analysis. NeuroImage 42, 343-356. doi: 10.1016/j.neuroimage.2008.04.025

${ }^{*} \mathrm{Wu}, \mathrm{T}$., and Hallett, M. (2005). A functional MRI study of automatic movements in patients with Parkinson's disease. Brain 128, 2250-2259. doi: 10.1093/brain/awh569

*Wu, T., Long, X., Wang, L., Hallett, M., Zang, Y., Li, K., et al. (2011). Functional connectivity of cortical motor areas in the resting state in Parkinson's disease. Hum. Brain Mapping 32, 1443-1457. doi: 10.1002/hbm.21118

Wurster, C. D., Graf, H., Ackermann, H., Groth, K., Kassubek, J., and Riecker, A. (2015). Neural correlates of rate-dependent finger-tapping in Parkinson's disease. Brain Struct. Funct. 220, 1637-1648. doi: 10.1007/s00429-014-0749-1

*Yan, L. R., Wu, Y. B., Zeng, X. H., and Gao, L. C. (2015). Dysfunctional putamen modulation during bimanual finger-to-thumb movement in patients with Parkinson's disease. Front. Hum. Neurosci. 9:516. doi: 10.3389/fnhum.2015.00516

Zeki, S., Watson, J. D., Lueck, C. J., Friston, K. J., Kennard, C., and Frackowiak, R. S. (1991). A direct demonstration of functional specialization in human visual cortex. J. Neurosci. 11, 641-649. doi: 10.1523/jneurosci.11-03-00641.1991

Zhang, L., Zhao, Y., Shen, C., Lei, L., Dong, J., Zou, D., et al. (2018). Can long-term regular practice of physical exercises including Taichi improve finger tapping of patients presenting with mild cognitive impairment? Front. Physiol. 9:1396. doi: 10.3389/fphys.2018.01396

Zhang, R., Geng, X., and Lee, T. M. C. (2017). Large-scale functional neural network correlates of response inhibition: an fMRI meta-analysis. Brain Struct. Funct. 222, 3973-3990. doi: 10.1007/s00429-017-1443-x

Ziegler, E., Rouillard, M., Andr,é, E., Coolen, T., Stender, J., Balteau, E., et al. (2014). Mapping track density changes in nigrostriatal and extranigral pathways in Parkinson's disease. NeuroImage 99, 498-508. doi: 10.1016/j.neuroimage.2014.06.033

Conflict of Interest: The authors declare that the research was conducted in the absence of any commercial or financial relationships that could be construed as a potential conflict of interest.

Publisher's Note: All claims expressed in this article are solely those of the authors and do not necessarily represent those of their affiliated organizations, or those of the publisher, the editors and the reviewers. Any product that may be evaluated in this article, or claim that may be made by its manufacturer, is not guaranteed or endorsed by the publisher.

Copyright (C) $2021 \mathrm{Li}, \mathrm{Liu}, \mathrm{Du}, \mathrm{Zhu}$, Qiu and Xu. This is an open-access article distributed under the terms of the Creative Commons Attribution License (CC BY). The use, distribution or reproduction in other forums is permitted, provided the original author(s) and the copyright owner(s) are credited and that the original publication in this journal is cited, in accordance with accepted academic practice. No use, distribution or reproduction is permitted which does not comply with these terms. 